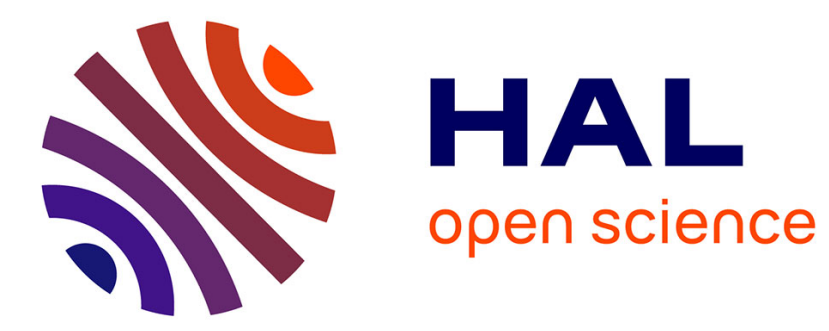

\title{
ABCG: a new fold of ABC exporters and a whole new bag of riddles!
}

Atanu Banerjee, Alexis Moreno, Jorgaq Pata, Pierre Falson, Rajendra Prasad

\section{To cite this version:}

Atanu Banerjee, Alexis Moreno, Jorgaq Pata, Pierre Falson, Rajendra Prasad. ABCG: a new fold of ABC exporters and a whole new bag of riddles!. Rossen Donev. Advances in Protein Chemistry and Structural Biology, 123, Elsevier, pp.163-191, 2021, 10.1016/bs.apcsb.2020.09.006 . hal-03125305

\section{HAL Id: hal-03125305 https://hal.science/hal-03125305}

Submitted on 29 Jan 2021

HAL is a multi-disciplinary open access archive for the deposit and dissemination of scientific research documents, whether they are published or not. The documents may come from teaching and research institutions in France or abroad, or from public or private research centers.
L'archive ouverte pluridisciplinaire HAL, est destinée au dépôt et à la diffusion de documents scientifiques de niveau recherche, publiés ou non, émanant des établissements d'enseignement et de recherche français ou étrangers, des laboratoires publics ou privés. 


\section{Chapter 8: ABCG: A new fold of ABC}

\section{exporters and a whole new bag of}

\section{riddles!}

Atanu Banerjee', Alexis Moreno², Jorgaq Pata ${ }^{2}$, Pierre Falson ${ }^{2 *}$ and Rajendra Prasad ${ }^{1,3 *}$

${ }^{1}$ Amity Institute of Biotechnology, Amity University Haryana, Gurgaon, India

${ }^{2}$ Drug Resistance \& Membrane Proteins team, Molecular Microbiology and Structural

Biochemistry Laboratory, CNRS-Lyon 1 University UMR5086, Institut de Biologie et Chimie des Protéines, Lyon, France

${ }^{3}$ Amity Institute of Integrative Sciences and Health, Amity University Haryana, Gurgaon, India

*corresponding authors: pierre.falson@ibcp.fr ; rprasad@ggn.amity.edu 


\section{Contents}

Abstract

Keywords

1. $\mathrm{ABC}$ transporters and their relevance

1.1 ABC transporter superfamily

1.2 General organization

1.3 Basis of transport mechanism

2. Structure of type I and type II exporters

2.1 Type I structures

2.2 Type II structures

2.2.1 ABCG5/G8

\subsubsection{ABCG2}

2.3 Substrate binding pockets

3. Yeast $\mathrm{ABCG} / \mathrm{PDR}$ transporters: contribution towards understanding the enigma of the non-catalytic nucleotide-binding site

4. Concluding thoughts and future perspectives

Acknowledgements

References

Table and Figure legends 


\begin{abstract}
ATP-binding cassette (ABC) superfamily comprises membrane transporters that power the active transport of substrates across biological membranes. These proteins harness the energy of nucleotide binding and hydrolysis to fuel substrate translocation via an alternating-access mechanism. The primary structural blueprint is relatively conserved in all ABC transporters. A transport-competent $\mathrm{ABC}$ transporter is essentially made up of two nucleotide-binding domains (NBDs) and two transmembrane domains (TMDs). While the NBDs are conserved in their primary sequence and form at their interface two nucleotide-binding sites (NBS) for ATP binding and hydrolysis, the TMDs are variable among different families and form the translocation channel. Transporters catalyzing the efflux of substrates from the cells are called exporters. In humans, they range from A to $\mathrm{G}$ subfamilies, with the $\mathrm{B}, \mathrm{C}$ and $\mathrm{G}$ subfamilies being involved in chemoresistance. The recently elucidated structures of ABCG5/G8 followed by those of ABCG2 highlighted a novel structural fold that triggered extensive research. Notably, suppressor genetics in the orthologous yeast Pleiotropic Drug Resistance (PDR) family proteins have pointed to a crosstalk between TMDs and NBDs modulating substrate export. Considering the structural information provided by their neighbors from the $\mathrm{G}$ family, these studies provide mechanistic keys and posit a functional role for the non-hydrolytic NBS found in several ABC exporters. The present chapter provides an overview of structural and functional aspects of ABCG proteins with a special emphasis on the yeast PDR systems.
\end{abstract}

\title{
Keywords
}

ABC transporter, ABCG family, PDR subfamily, nucleotide-binding domains, transmembrane domains, non-catalytic NBS 


\section{Abbreviations}

ABC: ATP binding cassette

ADP: adenosine-5'-

diphosphate

ATP: adenosine-5'-

triphosphate

Cdr1p: Candida drug

resistance protein 1

CFTR: cystic fibrosis

transmembrane conductance

regulator

$\mathrm{CnH}$ : connecting helix

$\mathrm{CpH}$ : coupling helix

cryo-EM: cryo electron

microscopy

ECD: extra cellular domain

ECF: energy-coupled factor

IFC: Inward-facing

conformation

MRP1: multidrug resistanceassociated protein 1

NBD: nucleotide binding domain

NBS: nucleotide binding site NTP: nucleoside triphosphate
OFC: Outward-facing

conformation

PDR: Pleiotropic drug

resistance

P-gp: P-glycoprotein

$\mathrm{P}_{\mathrm{i}}$ : inorganic phosphate

SUR: sulfonylurea receptor

TMD: transmembrane

domain

TMH: transmembrane helix 


\section{ABC transporters and their relevance}

\subsection{ABC transporter superfamily}

The $\mathrm{ABC}$ transporter superfamily is one of the most omnipresent family of membrane proteins found in all kingdoms of life. It includes importers (not detailed here) involved in the influx of nutrients, mostly found in prokaryotes and plants or in the particular energy-coupled factor (ECF) subfamily, and exporters that manage the efflux of many endobiotics (lipids, metabolites, pheromones, ...) and xenobiotics (antibiotics, antifungals, anticancer drugs, antigens) (Higgins, 2001; Cédric Orelle et al., 2019; Rees et al., 2009). Some exceptions remain such as the Cystic Fibrosis Transmembrane Receptor, CFTR, which acts as a chloride channel (Rich et al., 1990; Vergani et al., 2003) and the sulfonylurea receptors SUR1 (ABCC8) and SUR2 (ABCC9) that are part of a potassium channel complex (Bryan et al., 2007). In bacteria, $\mathrm{ABC}$ transporters like $\mathrm{LptB}_{2} \mathrm{FG}$ can also act as a lipopolysaccharide channel, and others like MacA as mechano-transducers, in concert with additional periplasmic and outer membrane proteins (Ford \& Beis, 2019). 

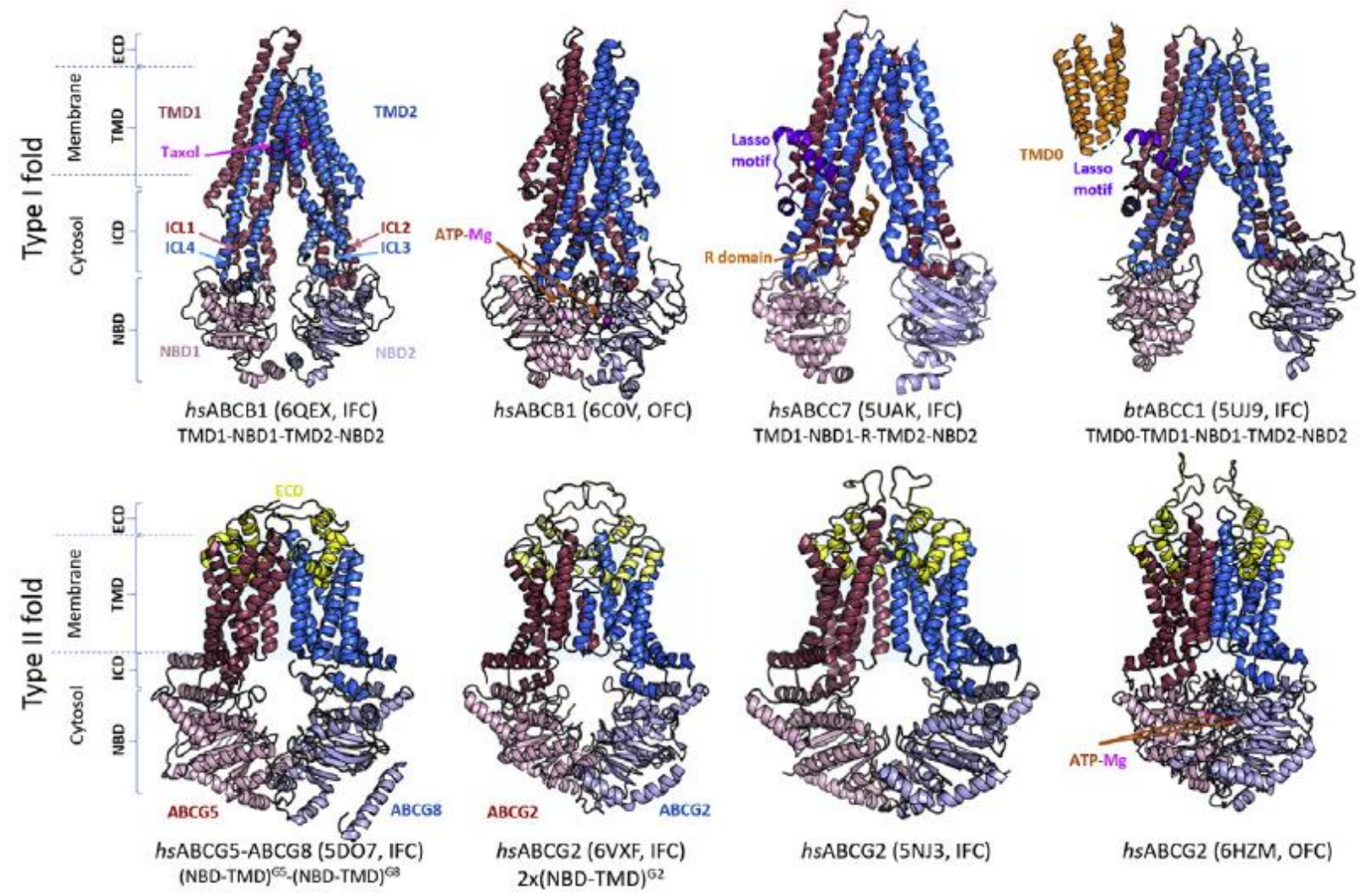

Figure 1. Cartoon representations of type I and type II ABC exporters structures, in inward- and outward-facing conformations (IFC, OFC). Human $\mathrm{ABCB} 1, \mathrm{ABCC} 7$ and ABCCC1 on the top belong to the type I fold. They are made of a single polypeptide organized in a pseudo-dimer of two haves (red and blue) forming the different regions, nucleotide-binding domains (NBDs), intracellular domain (ICD) with intracellular loops (ICLs), transmembrane domain (TMD) and extracellular domain (ECD). ABCC7 and $\mathrm{ABCC} 1$ display an additional regulatory domain and a transmembrane domain, respectively. Human ABCG5/ABCG8 and ABCG2 belong to the type II fold. They are made of two polypeptides making each half of the hetero- or homo- dimer. PDB codes are indicated. 
These proteins share a common sequence signature, called the $\mathrm{C}$ motif (detailed below) located in their two NBDs (Figure 1). Based on sequence similarities, eukaryotic proteins are classified into 9 families from $\mathrm{ABCA}$ to $\mathrm{ABCI}$, all comprising exporters except for the $\mathrm{ABCE}$ and $\mathrm{ABCI}$ subfamilies which include soluble $\mathrm{ABC}$ proteins devoid of transmembrane domain (Jeong et al., 2017; Navarro-Quiles et al., 2018). This nomenclature was first adopted by the HUGO Gene Nomenclature Committee for human transporters which are divided into 7 families from $\mathrm{ABCA}$ to $\mathrm{ABCG}$. The classification was further extended for non-mammalian proteins with the addition of the ABCH subfamily found in insects (Dean \& Annilo, 2005) and some fishes (Luckenbach et al., 2014; Popovic et al., 2010), and of the ABCI subfamily which is specific to plants (Verrier et al., 2008). The Pleiotropic Drug Resistance (PDR) subfamily is orthologous to the human $\mathrm{ABCG}$ and specific to plants and fungi. It is the largest one found in yeast, with 10 PDR transporters among 30 ABC proteins in S. cerevisia, 9 among 26 in C. albicans, and 7 among 25 in C. glabrata (Kumari et al., 2018; Prasad et al., 2016).

\subsection{General organization}

ABC pumps are made of two regions, one protruding in the cytosol in which ATP binds and is hydrolyzed and the other in the membrane through which solutes are translocated from one compartment to another, both functions dependent on each other. Each region is made at least of two domains, leading to the general topology (NBD-TMD) 2 per transporter. These domains are arranged either in full transporters in a single polypeptide $\mathrm{TMD}_{1}-\mathrm{NBD}_{1}-\mathrm{TMD}_{2}-$ $\mathrm{NBD}_{2}$ or $\mathrm{NBD}_{1}-\mathrm{TMD}_{1}-\mathrm{NBD}_{2}-\mathrm{TMD}_{2}$, or in half transporters in two identical or different polypeptides (TMD-NBD) 2 , (NBD-TMD) $)_{2}, \mathrm{TMD}_{1}-\mathrm{NBD}_{1}+\mathrm{TMD}_{2}-\mathrm{NBD}_{2}, \mathrm{NBD}_{1}-\mathrm{TMD}_{1}+$ 
$\mathrm{NBD}_{2}-\mathrm{TMD}_{2}$. In prokaryotes each domain of a single transporter can also be found as a single polypeptide. The PDR family, as the members of the human G subfamily, display the so-called "reverse topology" (NBD-TMD) compared to all others. Almost all of them are full plasma membrane-bound transporters.

The NBDs are well conserved in members of the ABC superfamily. They display highly conserved sequences required for ATP binding and hydrolysis, as detailed in Figure 2 and Table 1. Characteristic of the NTPases, these amino-acid sequences were initially designated $\alpha$ and $\beta$ folds, and further renamed Walker A and Walker B motifs, respectively (Saraste et al., 1990; Walker et al., 1982). The Walker A -or P-loop- GxxGxGKS/T, where $\mathrm{x}$ is any amino acid, binds the phosphate groups of the nucleotide, thanks to the contribution of amide groups from the backbone and the lateral chain of the lysine residue. The conserved serine/threonine residue participates in the coordination of the magnesium in complex with the nucleotide. The Walker B motif, hhhhDE where $\mathrm{h}$ is a hydrophobic residue, is also involved in the coordination of the metal. It is immediately followed by a catalytic glutamate residue that polarizes a water molecule required for the hydrolysis of the nucleotide (Oldham \& Chen, 2011; Szöllősi et al., 2018). Other conserved motifs were further discovered. The conserved glutamine of the Q-loop consensus sequence $\mathrm{h}(\mathrm{h} / \mathrm{Q}) \mathrm{Q}$ binds the magnesium and senses the nucleotide $\gamma$-phosphate (Yang et al., 2011), the histidine residue of the so-called H-loop stabilizes the phosphate hydrolysis (Zaitseva et al., 2005), and the aspartate residue of the D-loop SALD positions the attacking water molecule (Grossmann et al., 2014; Thomas \& Tampé, 2020). Altogether, these motifs define the RecA-like motor core of ABC-type ATPases, AAA+ and helicases (Ye et al., 2004). 
A hallmark of $\mathrm{ABC}$ proteins is the presence of two additional subdomains, one $\alpha$-helical, $\mathrm{ABC} \alpha$, and another made of antiparallel $\beta$-sheets, $\mathrm{ABC} \beta$ (Cedric Orelle et al., 2010; Smith et al., 2002) (Figure 3). ABC $\alpha$ contains the specific ABC consensus sequence (or Signature sequence or C-motif) LSGGQ (Hyde et al., 1990) that pins and orients the ATP (Moncalian et al., 2004; Rees et al., 2009). The glutamine residue of this sequence comes in close contact to the ribose moiety of the nucleotide. The ABC $\beta$ subdomain bears the conserved A-loop that consists of an aromatic residue that stabilizes the aromatic moiety of the nucleotide through $\pi$ - $\pi$-stacking interactions.

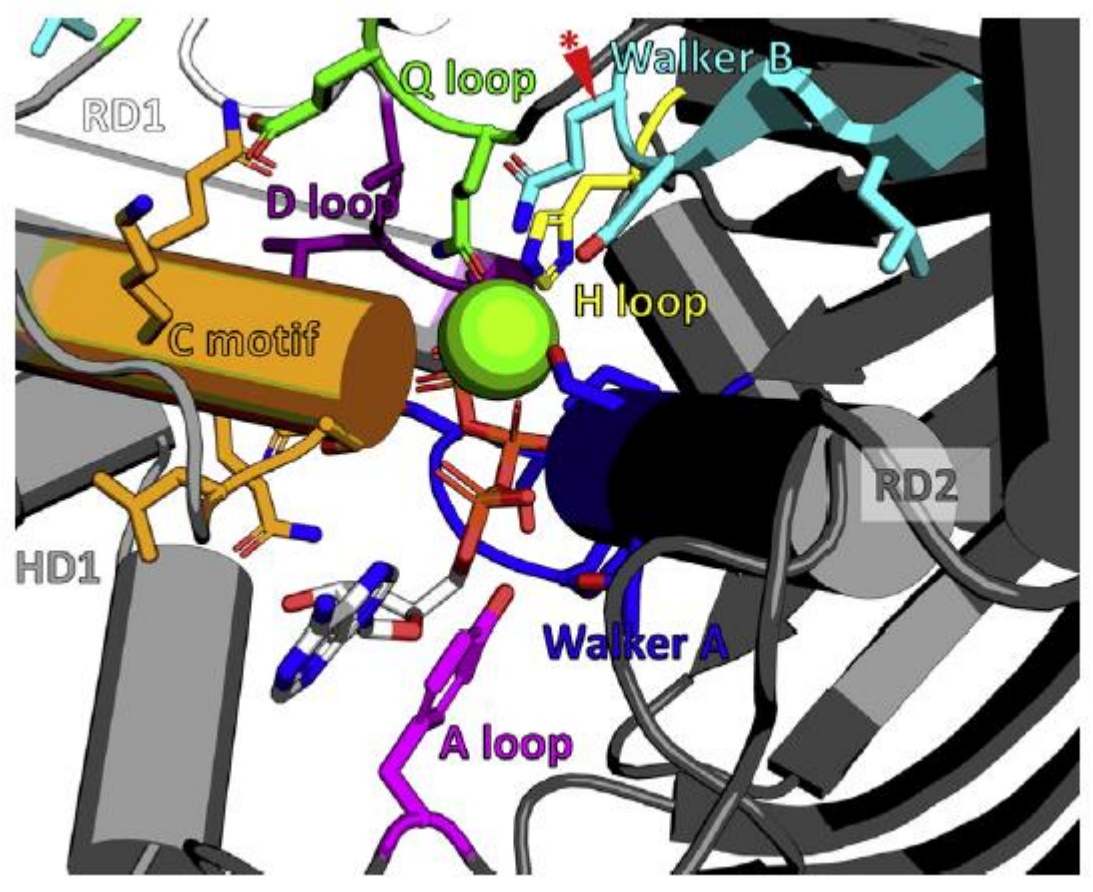


Figure 2. Nucleotide binding and hydrolysis motifs found in $\mathrm{ABC}$ transporters. Cartoon representation of the ATP-bound human P-gp E1201Q mutant (PDB ID: 6C0V) (Kim \& Chen, 2018) illustrating the different consensus peptides involved in binding and hydrolysis of the nucleotide. A glutamine residue (red star) in the Walker B motif replaces the glutamate 1201 to prevent ATP hydrolysis and maintain the protein in a pre-hydrolytic state. ATP is shown as sticks and magnesium as a sphere. HD1/HD2: helical domain 1/2 (ABC $\alpha$ subdomain), RD1/RD2: RecA-like domain 1/2 (including ABC $\beta$ subdomain). 
Table 1 Conserved sequence motifs of the nucleotide binding domains of $A B C$ proteins.

\begin{tabular}{|c|c|c|c|c|}
\hline Motif & $\begin{array}{l}\mathrm{ABC} \\
\text { consensus } \\
\text { sequence }\end{array}$ & $\begin{array}{l}\text { PDR catalytic } \\
\text { sequence }\end{array}$ & $\begin{array}{l}\text { PDR non- } \\
\text { catalytic } \\
\text { sequence }\end{array}$ & Function \\
\hline A loop & $\begin{array}{l}\text { Aromatic } \\
\text { residue }\end{array}$ & $\begin{array}{l}\text { Aromatic } \\
\text { residue }\end{array}$ & $\begin{array}{l}\text { Aromatic } \\
\text { residue }\end{array}$ & $\begin{array}{l}\text { Aromatic residue } \\
\text { interacting with } \\
\text { the adenine ring } \\
\text { of ATP }\end{array}$ \\
\hline $\begin{array}{c}\text { Walker A or } \\
\text { P-loop }\end{array}$ & $\begin{array}{c}\text { GxxGxGK } \\
(\mathrm{S} / \mathrm{T})\end{array}$ & $\begin{array}{c}\text { GxxGxGK } \\
(\mathrm{S} / \mathrm{T})\end{array}$ & $\begin{array}{c}\text { GxxGxGㅡㅡ } \\
(\mathrm{S} / \mathrm{T})\end{array}$ & $\begin{array}{l}\text { ATP/GTP binding } \\
\text { ( } \alpha-\text { and } \beta- \\
\text { phosphate } \\
\text { binding) }\end{array}$ \\
\hline Q-loop & Q & Q & $\underline{E}$ & $\begin{array}{l}\text { TMD-NBD } \\
\text { communication, } \\
\gamma \text {-phosphate } \\
\text { sensor }\end{array}$ \\
\hline $\begin{array}{l}\text { ABC } \\
\text { signature } \\
\text { motif or } \\
\text { C-loop }\end{array}$ & $\begin{array}{l}\text { LSGGQ } \\
\qquad(\mathrm{K} / \mathrm{R}) \mathrm{Q}\end{array}$ & VSGGERKR & LNVEQRKR & $\begin{array}{l}\text { ATP binding, } \\
\text { NBD-NBD } \\
\text { communication }\end{array}$ \\
\hline Walker B & hhhhDE & hhhhDE & hxxWDN & $\begin{array}{l}\text { ATP hydrolysis } \\
\text { (coordination of } \\
\text { catalytic water } \\
\text { and } \mathrm{Mg}^{2+} \text { ) }\end{array}$ \\
\hline D-loop & hLD & hLD & hLD & $\begin{array}{l}\text { NBD-NBD } \\
\text { communication }\end{array}$ \\
\hline $\begin{array}{l}\text { H-loop or } \\
\text { switch } \\
\text { region }\end{array}$ & $\mathrm{H}(\mathrm{Q} / \mathrm{R})$ & $\mathrm{H}(\mathrm{Q} / \mathrm{R})$ & $\underline{\mathrm{Y}}(\mathrm{Q} / \mathrm{R})$ & ATP hydrolysis \\
\hline
\end{tabular}

Table 1. Conserved sequence motifs of the nucleotide binding domains of $\mathrm{ABC}$

proteins. Residues are identified by their 1-letter code, $\mathrm{h}=$ hydrophobic residue, $\mathrm{x}=$ any amino acid. Based on Eggensperger and Tampé, 2015. 
RecA-like, $\mathrm{ABC} \alpha$, and $\mathrm{ABC} \beta$ subdomains form the minimal nucleotide-binding unit that requires dimerization to be functional. When they merge during the transport cycle, these subdomains generate two head-to-tail nucleotide-binding sites (NBSs) at their interface. Each NBS is made of motifs of the RecA-like subdomain and A-loop of one NBD and the C motif of the second one. Both NBS bind and hydrolyze ATP but some heterodimers and full transporters display divergent motifs in one NBS preventing the nucleotide to be hydrolyzed at this site. These divergent sequences are called deviant or degenerated. They are displayed in Table 1 . This is the case, for example of the human heterodimer ABCG5/G8 displayed in Figure 1, or that of the full transporters Pleiotropic drug resistance protein 5 (Pdr5p) of S. cerevisia or Candida drug resistance protein 1 (Cdr1p) of C. albicans. Initially thought to be degenerated to save energy, mutagenesis studies of Pdr5p and Cdr1p now point to a specific role of this non-hydrolytic site that modulates both the ATPase and drug-transport activities (see section 3) (Banerjee et al., 2018, 2020; Ernst et al., 2008; Prasad et al., 2019; Saini et al., 2006). 

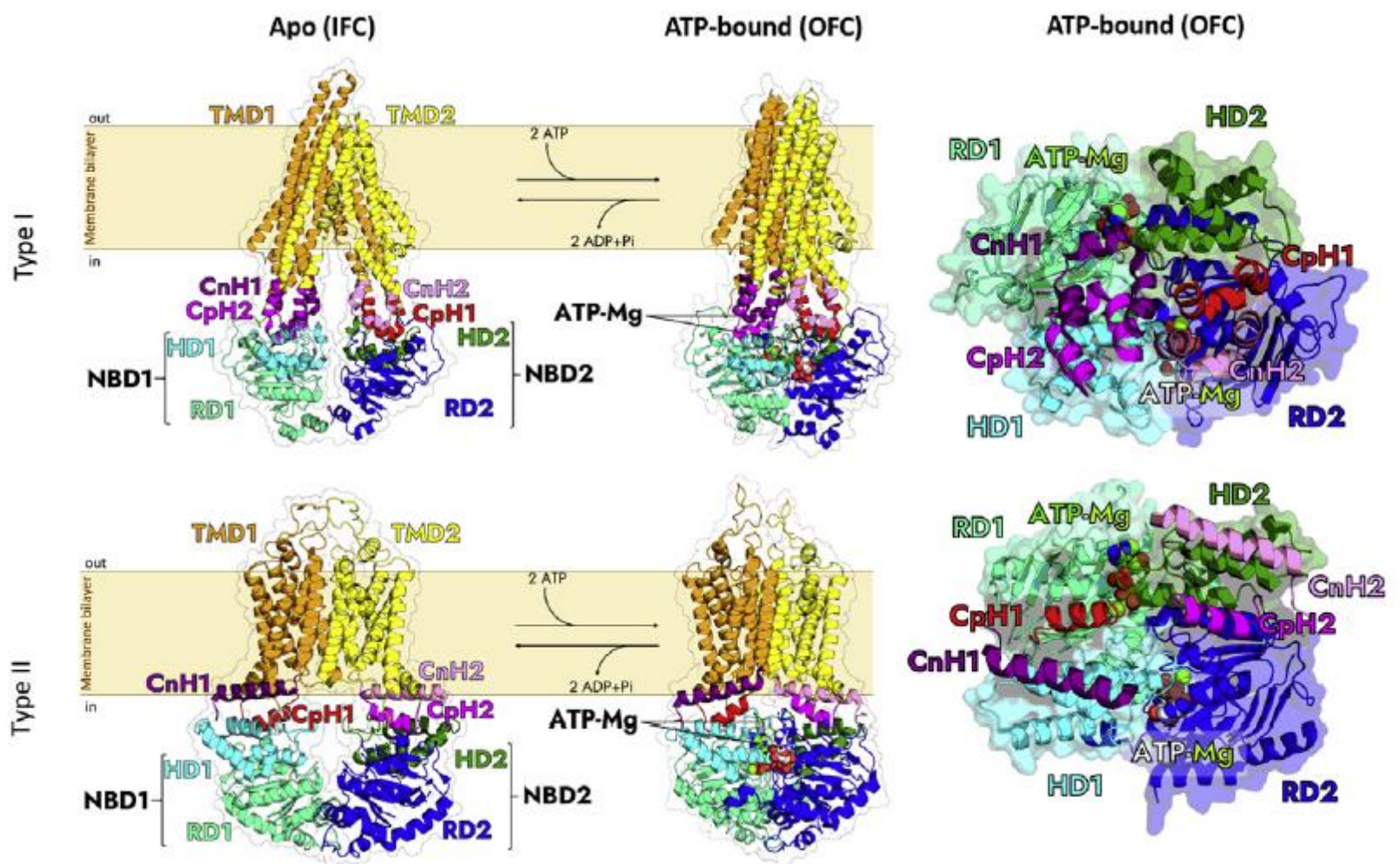

Figure 3. Domain organization of type I and type II ABC exporters. Left panels: IFC and $\mathrm{OFC}$ of ABCB1 (top, PDB ID: 6QEX and 6C0V, respectively) (Alam et al., 2019; Kim \& Chen, 2018) and of ABCG2 (bottom, PDB ID: 6VXF and 6HBU, respectively) (Manolaridis et al., 2018; Orlando \& Liao, 2020) illustrate the differences in interdomains connections between the two types of exporters and the major conformational switch involved in substrate transport. Proteins are represented as cartoon with their corresponding surface outlined and colored by domains and structural features. ATP- $\mathrm{Mg}^{2+}$ are shown as spheres. Right panels: Close view of the ATP-bound dimerized NBDs, as seen from the membrane, with surrounding semi-transparent surface. The coupling helices of both types of exporters make contacts with both the RecA-like and helical subdomains. In type I exporters (top), the connecting helices interact with the RecAlike domain of its opposite NBD. In contrast, the connecting helices of type II exporters (bottom) 
interact with the helical domain of its corresponding NBD. CnH1/2: connecting helix 1/2, CpH1/2: coupling helix 1/2, HD1/HD2: helical domain 1/2 (ABC $\alpha$ subdomain), NBD1/2: nucleotide binding domain 1/2, RD1/RD2: RecA-like domain 1/2 (including $A B C \beta$ subdomain), TMD1/2: transmembrane domain $1 / 2$.

TMDs are generally made of 6 helices going through the membrane, however some $\mathrm{ABC}$ pumps can have an additional membrane region, such as the TMD0 of ABCC1 (Figure 1). As for NBDs, TMDs generate a functional site at their interface, of which the shape depends on the type of pumps (see section 2.3). Contrary to NBDs residues, TMDs show poor conservation. This is because their interaction with the surrounding lipids can be done with various aliphatic or aromatic residues and because residues forming the translocating pocket vary with the type of substrate transported. A deep mutagenesis study carried out on the 250 residues forming the membrane region of Cdr1p allowed to sort about $1 / 3$ critical for antifungals, dyes and steroids transport (Baghel et al., 2017; Nim et al., 2016). Interestingly, these studies suggest a molecular basis of polyspecificity that characterizes this pump close to that of Mdr1p, the major drug/ $/ \mathrm{H}^{+}$ antiporter of C. albicans. Mdrlp also confers multidrug resistance to the yeast, and the same global mutagenesis strategy carried out revealed that the structural basis for its polyspecificity is an extended capacity brought by residues located at the periphery of a binding core to accommodate compounds differing in size and type (Redhu et al., 2018).

\subsection{Basis of transport mechanism}


Functionally, $\mathrm{ABC}$ transporters follow the much earlier conceptualized and general alternating access mechanism (Jardetzky, 1966). Following this concept, the pump undergoes two main conformational changes by which a substrate in the internal compartment (e.g. cytoplasm) binds to the membrane cavity and is then translocated to the external compartment (e.g. extracellular space). These two states correspond to the inward- and outward-facing conformations, IFC and OFC, illustrated in Figures 1 and 3.

Roughly, the transport cycle carried out by ABC pumps starts in IFC with the binding of the substrate, also called allocrite to distinguish from ATP-Mg which is the substrate of the ATPase activity (Holland, 2011), to a cavity into the TMDs accessible from the inner compartment. The substrate binding triggers/stabilizes the fusion of the two NBDs that generates the NBSs on which bind the nucleotide-Mg complexes. This binding locks the pump in an occluded state by which the substrate cannot escape back to the inner compartment and triggers its translocation through an IFC - OFC transition. The OFC exposes the membrane cavity to the outer space that promotes release of the substrate. The substrate release triggers another conformational change that triggers ATP hydrolysis and resets the pump to its initial IFC.

The stoichiometry of hydrolyzed ATP versus transported molecules remains unclear. Several mechanisms have been proposed over time and most recent evidences suggest a binding and hydrolysis of the two ATP molecules in a sequential and asymmetric manner (Orelle et al., 2019). However, this cannot be a consensus mechanism since, as introduced above, several ABC transporters harbor a non-hydrolytic NBS. Photolabeling and structural experiments performed in the multidrug resistance-associated protein 1, MRP1/ABCC1, (Wang et al., 2020) and in the bacterial TM287/288 from Thermotoga maritima (Furuta et al., 2016; M. Hohl et al., 2014; 
Hutter et al., 2019), together with electrophysiological and structural studies of the human and zebrafish CFTR (Basso et al., 2003; Vergani et al., 2005; J. Zhang et al., 2018; Z. Zhang et al., 2018) have shown that the NBDs dimer has a looser interface at the non-hydrolytic NBS as opposed to the catalytic one where ATP is quickly hydrolyzed.

\section{Structure of type I and type II exporters}

Based on their architecture, $\mathrm{ABC}$ exporters are so far classified into two distinct folds named type I and type II as displayed in Figures 1 and 3. Several structures in both types have been obtained in these states.

\subsection{Type I structures.}

In 2006, Kaspar Locher and his team were the first to release an OFC structure of a type I exporter, Sav1866 from Staphylococcus aureus, resolved by X-ray crystallography in complex with ADP (Dawson \& Locher, 2006). Geoffrey Chang and his team then released several X-ray apo, IFC and OFC structures of MsbA from Escherichia coli, Vibrio cholera and Salmonella typhimurium, in complex with AMP-PNP, a non-hydrolysable analog of ATP (Ward et al., 2007). They then released the X-ray IFC structures of the mouse P-gp, apo or in complex with 2 different cyclic peptides (Aller et al., 2009), acting as inhibitors of the transport of the dye Hœchst 33342 and the anticancer drug doxorubicin (Martinez et al., 2014). They completed this panel with other close IFC X-ray structures of the same protein (Ward et al., 2013). The first structure of a heterodimeric ABC exporter, with one non-catalytic NBS, was released by the group of Markus Seeger, TM287/288 (Michael Hohl et al., 2012). Jue Chen and her team released the X-ray IFC structure of the P-gp from Canorhabditis elegans (Jin et al., 2012) and 
more recently by cryo-electron microscopy (cryo-EM) those of the bovine MRP1/ABCC1 (Johnson \& Chen, 2017) and human CFTR/ABCC7, apo and in complex with ATP-Mg (Liu et al., 2017; Zhang et al., 2018). This was recently followed by the cryo-EM structure of the human P-gp/ABCB1 apo or in complex with the inhibitor zosuquidar by Kaspar Locher and is team (Alam et al., 2018). Other X-ray and cryo-EM structures were also released, such as that of ATM1, either from S. cerevisiae, apo and in complex with glutathione (Srinivasan et al., 2014) or from Novosphingobium aromaticivorans (Lee et al., 2014).

All these structures display the same overall topology. The membrane region is linked to the cytosolic nucleotide-binding region by a large intracellular domain (ICD) made of a pair of long hairpin-like loops (Figures 1 and 3). In IFC, the drug-binding pocket can be as large as 6000 $\AA^{3}$. Another remarkable feature exists in the inter-domain communication, in between each moiety/monomer, and between TMDs and NBDs. The first one is generated by a domain swapping by which the coupling helix $(\mathrm{CpH})$ connecting membrane helices 4 and 5 of one moiety/monomer protrudes outside the membrane to come in contact with the NBD of the other moiety/monomer. The second one is the connecting helix $(\mathrm{CnH})$, made of a similar contact between a second helical hairpin connecting membrane helices 2 and 3 and the NBD, but herein, within the same moiety/monomer (Figure 3).

\subsection{Type II Structures}

\subsubsection{ABCG5/G8}

In 2016, the teams of Helen Hobs and Daniel Rosenbaum released the crystal structure of the human sterol transporter, ABCG5/G8, the first of the G subfamily and homologs (Lee et al., 
2016). ABCG5/G8 mediates the extraction of sterols in liver and intestines and mutations cause sitosterolemia, a disorder characterized by an accumulation of sterols in blood and tissues (Berge et al., 2000). The protein, made of two different moieties NBD-TMD G5 and G8, revealed a fold deeply differing from that of type I. This new fold is characterized by an absence of domain swapping, NBDs in close-contact to the TMDs, the latter generating at their interface a large but narrow substrate-binding cavity. The pump also displays a large extracellular domain (ECD) between TM5 and TM6, in which, notably, two half-membrane helices penetrate and go out the outer leaflet of the membrane as a fold never observed before in the $\mathrm{ABC}$ exporters. In vicinity of these helices, the authors identified densities in the crystallographic map that possibly fit with cholesterol molecules. It was therefore proposed that the ECD may facilitate the exit of sterols. The crosstalk between NBDs and TMDs, a key feature of the transport cycle, is mediated by a bundle of coupling helix $(\mathrm{CpH})$, connecting helix $(\mathrm{CnH})$ and an E-helix (E corresponding to a conserved glutamate residue) through an array of $\mathrm{H}$-bonds and salt bridges, altogether making a small ICD. A relay of polar residues extends from this bundle to the TMD interface, to confer flexibility and to lower the barrier energy for the different domain motions, a hypothesis supported by mutations in this relay that disrupt the function of the transporter (Lu et al., 2001).

\subsubsection{ABCG2}

ABCG2 was initially identified as the breast cancer resistance protein, BCRP, for its protector role across physiological barriers by expelling xenobiotics (Gutmann et al., 2005; Mao, 2008). ABCG2 was also localized in kidney proximal tubular cells in which it mediates the efflux of urate, for which the Q141K polymorphism increases the risk of gout (Qiu et al., 2014; 
Woodward et al., 2009). Together with at least ABCB1 and ABCC1, ABCG2 confers a multidrug resistance phenotype by expelling anticancer drugs (Tamaki et al., 2011).

The functional protein comprises two identical subunits displaying the typical NBDTMD topology of that subfamily. ABCG2 exports a wide range of natural compounds, including porphyrins (Jonker et al., 2002; Partha Krishnamurthy et al., 2004, 2007) for which the ECD of ABCG2 is required for export (Desuzinges-Mandon et al., 2010), folic acid (Chen et al., 2003) and urate (Woodward et al., 2009). ABCG2 also exports different classes of anti-tumor drugs (Doyle \& Ross, 2003; Elkind et al., 2005; Robey et al., 2004) and fluorescent dyes (Özvegy et al., 2002). For a complete review see (P. Krishnamurthy \& Schuetz, 2006; Robey et al., 2018; Sarkadi et al., 2004).

Several cryo-EM structures of ABCG2 came up recently. The first one was an apo structure in complex with two antigen binding fragments (Fab) of the monoclonal antibody 5D3 (Taylor et al., 2017). The structure confirmed the general new type II fold discovered with ABCG5/G8. The TMD interface is formed by membrane helices 2 and 5 of each monomer and, due to a backbone shift of these helices, an inward-facing slit-like cavity is observed. A specific feature of $\mathrm{ABCG} 2$ in that conformation is a second small cavity below the ECD and above the main drug-binding cavity, separated from the latter by a plug formed by a di-leucine motif (L554-L555) and inaccessible in this state (Figure 4). This small cavity is limited by the ECD, which acts as a lid. This small cavity may accommodate substrates with low affinity. 

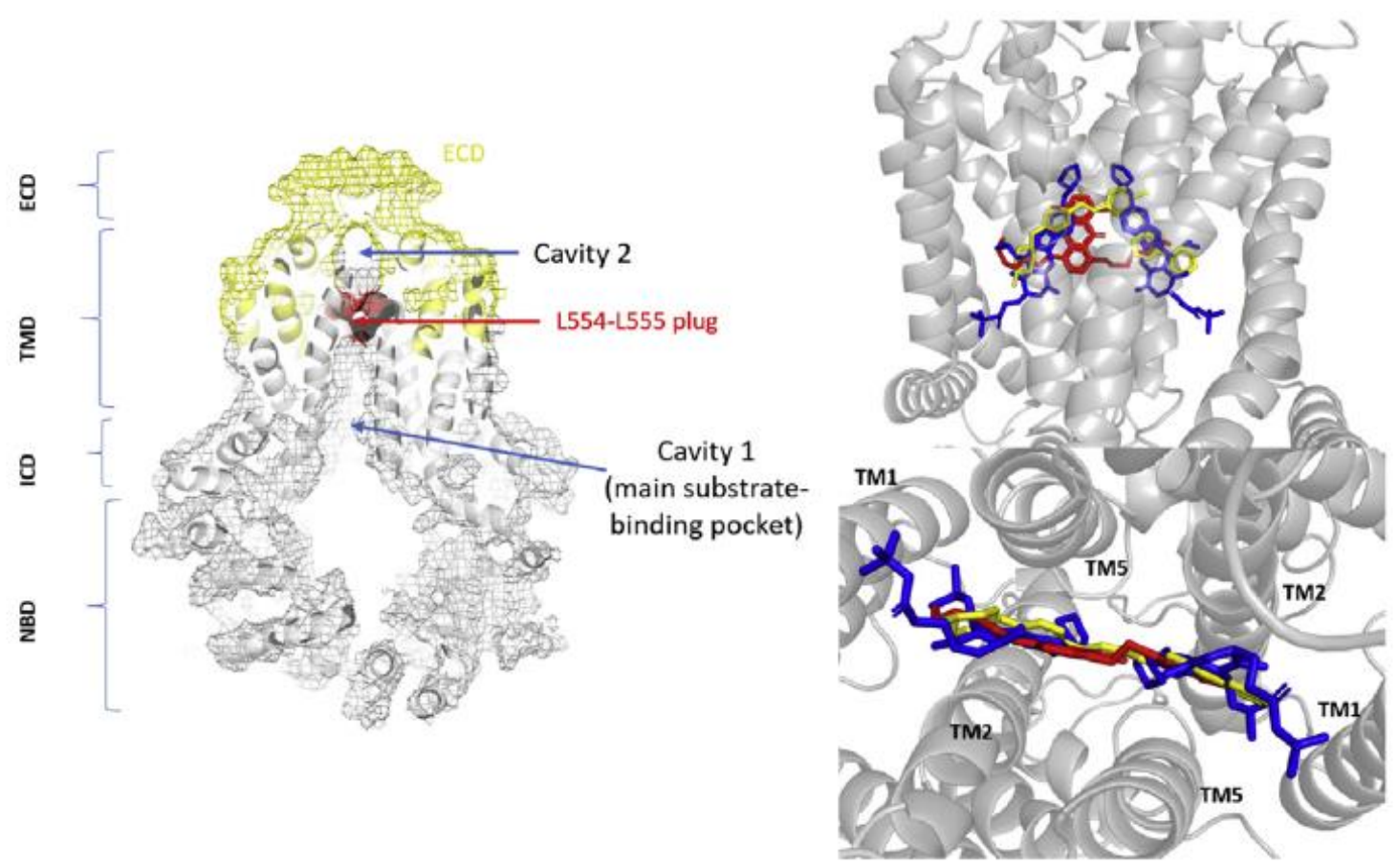

Figure 4. Details of the substrate-binding pocket of ABCG2. Left panel: mesh representation of ABCG2 (5NJ3) (Taylor et al., 2017) highlighting cavities 1 and 2. So far, no substrate has been found binding to the upper one. Right panels: zoomed cartoon representation of ABCG2 structures in complex either with the inhibitor MZ29 (blue) (6FFC) (Jackson et al., 2018), or the substrate mitoxantrone (red) (6XVI) or imatinib (yellow) (6XVH) (Orlando \& Liao, 2020), seen in the plan of the membrane (top) or seen from the NBDs (bottom).

In a follow-up article, Kaspar Locher and his team showed that the main membrane cavity binds ligands, resolving the structure of ABCG2 in complex with inhibitors (Jackson et al., 2018). Two molecules of MZ29, a new inhibitor derived from well-known Ko143 (van Loevezijn et al., 2001), were localized, occupying the whole main cavity near the two-fold symmetry axis of ABCG2 (Figure 4). The binding is assured by hydrophobic interactions 
involving residues L555, F431, F432 and M549, and H-bonds involving residues T435 and N436. By contrast, another inhibitor, the MB136 which is a derivative of tariquidar (Roe et al., 1999), was localized in a single copy in the homodimer, in a region overlapping that of MZ29. Residues F432, F439 and V546 were found to interact with the compound. In this IFC conformation no NBS is generated, as for type I exporters. However, the cytoplasmic extremity of each NBD is in contact with the other via a NPDXF motif, as also observed with ABCG5/G8.

Further, the same group released the structure of $\mathrm{ABCG} 2$ bound to a substrate in $\mathrm{OFC}$, or bound to two ATP-Mg in OFC, revealing for the first time such state of an ABCG subfamily transporter (Manolaridis et al., 2018). The substrate used for the study, the estrone-3-sulphate, was found to bind near to the two-fold symmetry axis of ABCG2, in the same cavity where the two MZ29 were also localized. This demonstrated the polyspecific binding capacity of ABCG2. Mutations of certain residues implicated in binding such as N536A and F439A abolish the transport activity, while V546F impairs the transport and increases the ATPase activity. Of note, these residues were also identified to prevent the binding of inhibitor. Mutants Y432A and A540F of ABCG5/8, equivalent to F439A and V546F in ABCG2, abolish the transport of sterol, hinting at a common architecture of this binding pocket amongst G-subfamily transporters (Lee et al., 2016).

Other structural data came from an article earlier in 2020 (Orlando \& Liao, 2020), reporting structures of $\mathrm{ABCG} 2$, firstly in apo state in a different conformation than that of initially released (Figure 1), and also with bound drugs, imatinib, mitoxantrone and SN38 (Figure 4). This new conformation (PDB: 6VFX) displays substantial differences with the previous structure (PDB 5NJ3). There is a rearrangement of the membrane helices, close to an 
OFC, with the large substrate-binding cavity fully collapsed. This is due to a shift of the membrane helix 5, in which residues are close to those of membrane helix 1 and 2 of the other monomer. At the interface between the two monomers, a cluster of sulfur-containing residues is observed, M541, M548, M549 and C544. Their side chains, along with that of F545 are oriented towards the opposing monomer, in contrast with previous structures. Regarding the substratebound structures, they look close to that of ABCG2 in complex with MZ29 or 5D3-bound ones, including residues interacting with substrates, as F432, F439 and F545. The authors brought evidences that this apo-closed structure having a collapsed substrate-binding cavity is relevant in cells. In this context, it seems that substrate or 5D3 binding causes a rearrangement of the TMDs to give the shape of the binding cavity initially observed. Another possibility would be that several conformations of TMDs are co-existing in cells, and substrate molecules bind to the proteins whose cavity is accessible.

\subsection{Substrate-binding pockets}

The structures of ABCG family proteins revealed several differences compared to other $\mathrm{ABC}$ human transporters. It has been reported that $\mathrm{ABCG} 2$ confers to cancer cells a multidrug resistance phenotype, due to its ability to bind and extrude drugs of different classes. However, compared to other MDR transporters, like P-gp (ABCB1) or MRP1 (ABCC1), despite the common substrates, there are yet some specificities for each of the transporters.

With the 3D structures of these proteins having been resolved, we are now in a better position to understand the way that these proteins bind their substrates. The previously mentioned structural studies revealed how the ABCG2 binding pocket is optimal to 
accommodate flat polycyclic substrates, in a slit-like manner, whereas $\mathrm{ABCB} 1$ displays a globular pocket, where large substrates such as Taxol can be accommodated (Alam et al., 2019; Aller et al., 2009) (Figure 5). As for ABCC1, the structures have revealed a bipartite pocket, with one part accommodating hydrophobic substrates and the other part, positively charged, accommodating glutathione, since many substrates need to be conjugated to the latter to be transported (Johnson \& Chen, 2017).

In the case of $\mathrm{ABCG} 2$, structures released so far show that substrates and inhibitors bind and overlap in the cavity situated in the crevice between monomers. However, more information is needed to fully understand the transport cycle and the transmission interface between TMD and NBD, and some interesting polymorphisms, like the mutations of R482, changing the substrate spectrum of the protein, even though this residue is not part of the binding pocket (Alqawi et al., 2004; Ejendal et al., 2006), suggesting a possible allostery.

Furthermore, 3D structures, mutagenesis and molecular dynamics have shown the presence of a valve, or plug, through which, ABCG2 substrates must pass before getting transported outside of the cell (Khunweeraphong et al., 2019). This plug is composed of residues G553 to T559, with two leucine residues, L554 and L555, standing on the top of the cavity, at the interface, and facing each other. This stretch of residues is highly conserved amongst ABCG and PDR members, and it is required for the proper transport function of the protein. Substrate may need to pass through this valve before entering the before mentioned second cavity, which is limited by extracellular loops, the re-entry helix and the TM extremities. This region itself behaves as a lid, allowing the expulsion of the substrates and avoiding their re-entry in the upper cavity. 


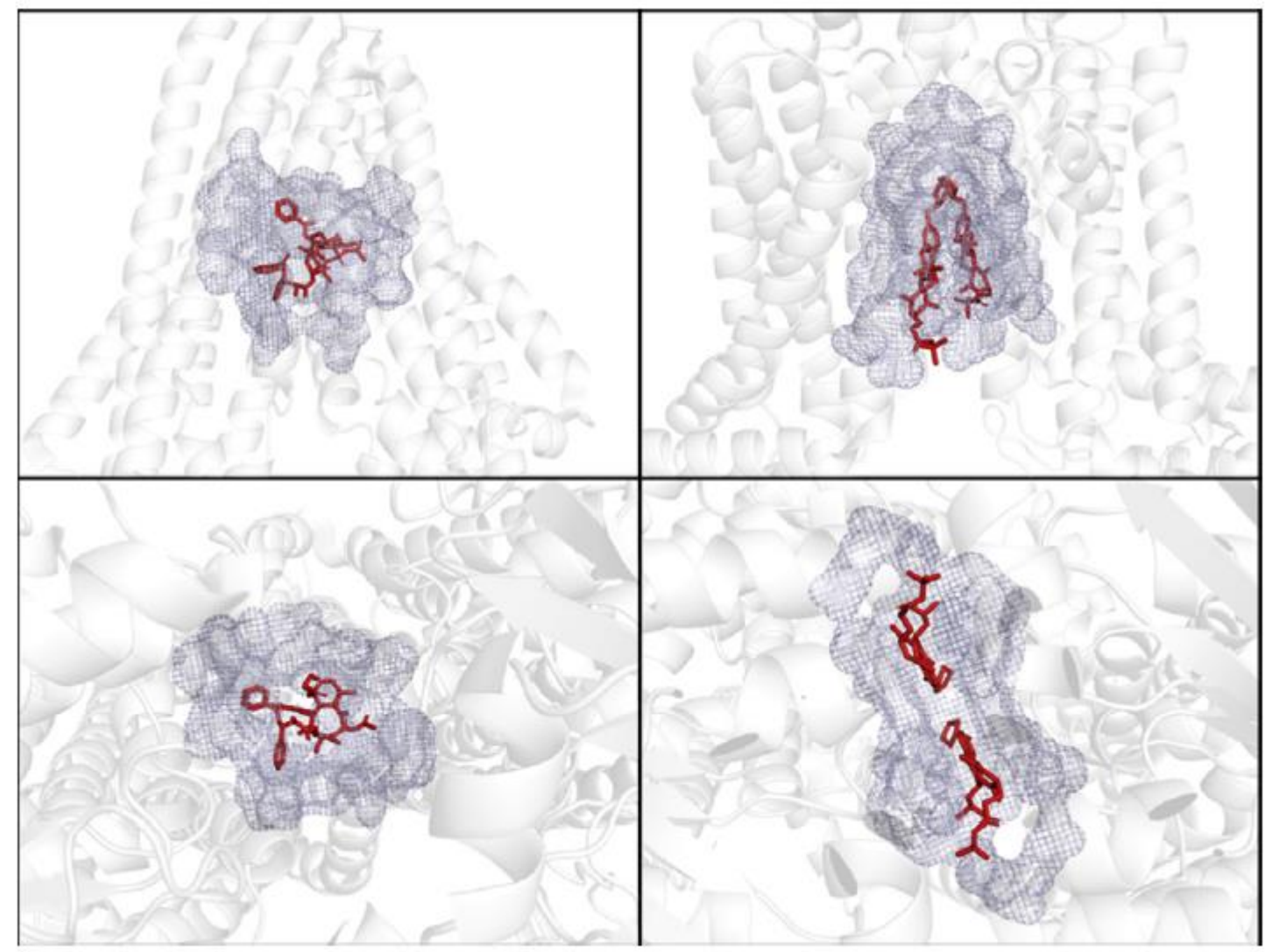

Figure 5. Shapes of type I and type II substrate-binding pockets. Left: ABCB1 in complex either with taxol (red) (6QEX) (Alam et al., 2019) seen in the plane of membrane (top) or seen from NBDs (bottom), with the interacting residues represented as a mesh (blue), putting in evidence the globular shape of the type I substrate-binding pocket. Right: ABCG2 in complex with its inhibitor MZ29 (red) (6FFC) (Jackson et al., 2018) seen in the plane of membrane (top) or seen from NBDs (bottom), with the interacting residues represented as a mesh (blue), putting in evidence the slit-like shape of the type II substrate-binding pocket, accommodating flat hydrophobic compounds. 


\section{Yeast ABCG/PDR transporters: contribution towards understanding the enigma of non-catalytic nucleotide-binding sites}

The yeast PDR transporters display many unique attributes at the level of sequence, structure as well as function. Beside the already mentioned reverse topology, these pumps are characterized by a large $N$-terminal cytosolic domain that includes the $N$-terminal NBD (Moreno et al., 2019). Moreover, the most striking structural feature is the presence of a large ECD made of two long ECLs, ECL3 and partially homologous ECL6 (Lamping et al., 2010). Furthermore, PDR transporters are also asymmetric in nature, like many other clinically relevant counterparts such as CFTR/ABCC1, MRP1/ABCC7 and the Transporter associated with Antigen Processing TAP1/TAP2 proteins (Gao et al., 2000; Procko et al., 2006; Sorum et al., 2017). Even though two NBSs exist, only NBS1 participates in the ATP hydrolysis process. Interestingly, while this catalytic NBS comprises of consensus sequences, NBS2, the non-catalytic NBS contains the socalled "deviant" sequences (Golin \& Ambudkar, 2015), quite typical in the case of PDR transporters (Table 1).

It is important to mention that the "deviant site" sequences are conserved among the PDR transporters, implying a plausible functional importance of this non-catalytic NBS (Moreno et al., 2019). This claim is further strengthened by the observation that chimeras made of either two $N$-NBDs or two $C$-NBDs of $C$. albicans $C d r 1 \mathrm{p}$ are both inactive, hinting to towards functional role of both NBDs in drug transport mechanism (Saini et al., 2006). Furthermore, a more recent attempt by Gupta et al. to restore symmetry in the NBS of asymmetric Pdr5p also witnessed similar fate, with varying order of loss of function observed in the mutants generated 
for each motif (Gupta et al., 2014). Contrarily, the pieces of evidence from asymmetric proteins other than PDR ones are suggestive of negligible contribution from the non-catalytic NBS in the general catalysis mechanism and define the catalytic NBS as the primary facilitator of transport (Procko et al., 2006; Tsai et al., 2010). Another remarkable feature of the PDR pumps is their constitutively active hydrolysis machinery, which is not stimulated by its substrates (Ernst et al., 2010; Prasad et al., 2015). This particular feature is in stark contrast to other ABC pumps like Pgp/ABCB1, which demonstrates manifold increase in ATP-hydrolysis on exposure to its substrates (Urbatsch \& Senior, 1995). Together, the yeast PDR transporters contrast other ABC transporters on many fronts, and there is also a constant debate on the contribution of the noncatalytic NBS, wherein the PDR pumps support an active role unlike many other ABC pumps. In that line, the ease of genetic manipulation in yeasts has provided a strong impetus in solving the conundrum of active $v s$ passive role for the non-catalytic NBS.

Following the suppressor genetics strategy, yeast cells expressing transport-defective single Cdr1p/Pdr5p mutants are exposed to toxic concentrations of xenobiotic substrates, forcing them to generate compensatory mutations alleviating the toxicity. Suppressor mutations are frequently recovered from a secondary site within the target protein. John Golin's group found early success with this strategy while studying Pdr5p transport. Initially the group identified the single mutation S558Y within the membrane helix 2 that rendered the pump-overexpressing yeast several-fold susceptible towards the favored Pdr5p's substrate cycloheximide, without however modifying the ATPase activity of Pdr5p (Sauna et al., 2008). Further, the authors submitted yeast cells expressing that mutant to the suppressor strategy and identified a secondary mutation $\mathrm{N} 242 \mathrm{~K}$ located close to the Q-loop of $N$-NBD, which is part of the non-catalytic NBS, 
which reversed the initial phenotype rendering the yeast expressing the Pdr5p S558Y-N242K double mutant, resistant to cycloheximide (Sauna et al., 2008) (Figure 6). Following the same strategy, John Golin and his colleagues identified another second-site mutation K1016I from the N242K mutant, rescuing the yeast. K1016 is located close to the Signature sequence of the noncatalytic NBS (Downes et al., 2013). Interestingly, amongst all the suppressor mutations that alleviated the S558Y transport defect, a significant number of them were always located either close to or within the Q-loop of the non-catalytic NBS (Ananthaswamy et al., 2010). All these findings hinted towards a plausible role of the non-catalytic NBS in signal transmission or interdomain crosstalk. Few studies that followed provided further strength to this claim. Furman et al. in their study with the D-loop mutants identified a D1042N mutation displaying uncoupling of ATPase activity and drug efflux (Furman et al., 2013). Notably the residue is also part of the non-catalytic NBS. Moreover, the study by Gupta et al. (discussed above) also described several deviant-to-consensus mutants demonstrating phenotypes like uncoupling of ATP hydrolysis and substrate transport (Gupta et al., 2014). The authors concluded that the substitutions in the noncatalytic NBS primarily led to defects in the crosstalk between the two NBSs and/or between the $\operatorname{NBS}(\mathrm{s})$ and TMD(s). 


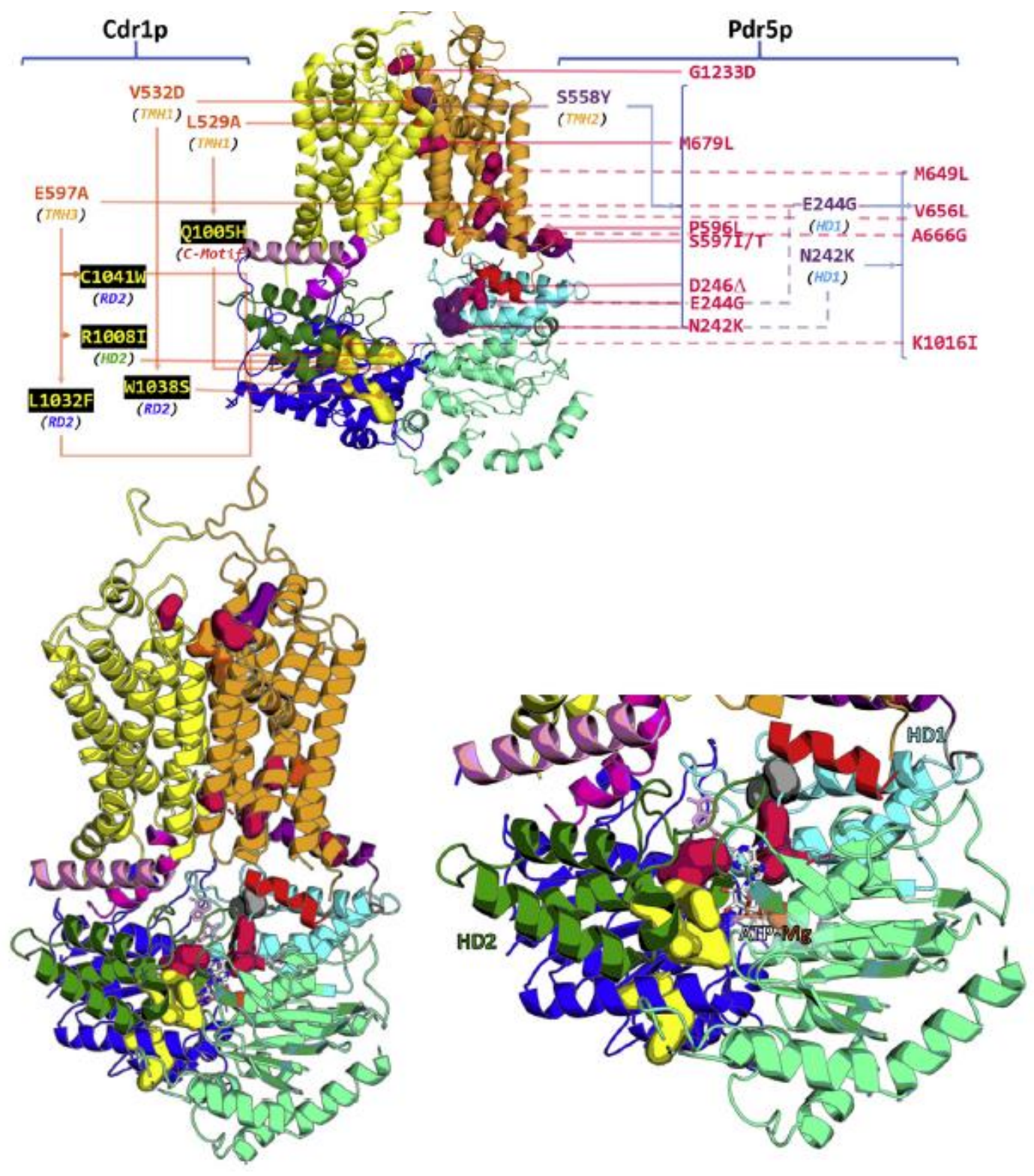

Figure 6. Mapping of primary drug-sensitive and secondary rescuing mutants in

yeast type II exporters Cdr1p and Pdr5p. Upper panel: 3D IFC models of Cdr1p and Pdr5p (Banerjee et al., 2020) with functional regions colored as described in Figure 3. Primary drugsensitizing mutants are S558Y (Sauna et al., 2008), N242K and E244G (Downes et al., 2013) in Pdr5p, and E597A (Shah et al., 2015; Shah et al., 2015), V532D (Banerjee et al., 2018) and 
L529A (Rawal et al., 2013) in Cdr1p. S558Y in Pdr5p is rescued by the secondary mutations N242K, E244G, D246ム, S597I/T, M679L, P596L or G1233D; N242K is rescued by K1016I, V656L, P596L, L1367F, A670S, or I1063M; E244G is rescued by V656L (Sauna et al., 2008; Ananthaswamy et al., 2010; Downes et al., 2013). E597A, V532D and L529A in Cdr1p are rescued by C1041W, R1008I and L1032F for the first one and W1038S and Q1005H, respectively, for the last two (Banerjee et al., 2018; Banerjee et al., 2020). Lower panel, left: OFC model of ATP-Mg bound Cdr1p (Banerjee et al., 2020) colored as above with primary drug-sensitizing and suppressor mutants of Cdr1. Residues corresponding to those of Pdr5p are also displayed with the same color code. Right: zoom to the non-hydrolytic NBS.

Investigation with the C. albicans Cdrlp counterpart by the group of Rajendra Prasad led to similar conclusions, pointing this time to the $C$-part of the non-hydrolytic NBS of the pump. Shah et al. identified three suppressors for one of the ICL1 mutant, E597A, that mapped to the non-catalytic NBS (Shah, Banerjee, et al., 2015; Shah, Rawal, et al., 2015). Out of the three, while two were located close to the D-loop, one mapped close to the Signature sequence. Of note, E597A mutant also demonstrated uncoupling of ATPase activity and substrate transport, whereby the cells overexpressing the variant demonstrated reduced transport and active ATPase machinery. Two more recent studies by Rajendra Prasad and Pierre Falson groups further provided mechanistic insights into the active involvement of the non-catalytic NBS in the transport cycle of PDR pumps. The authors exploited suppressor genetics approach on two transport deficient TMD mutants, V532D and L529A. While V532D shows defect in both ATPase activity and substrate transport, L529A is ATPase competent but shows substrate 
binding and transport defects. When the V532D expressing S. cerevisiae strain was exposed to ketoconazole, a suppressor strain survived, harboring the second-site mutation W1038S (Banerjee et al., 2018) (Figure 6). The position of the residue is close to the D-loop of the noncatalytic NBS. The transport was restored in the suppressor strain V532D-W1038S for most of the substrates and its ATPase activity was further reduced and showed hypersensitivity towards ketoconazole. Homology model built using ABCG5/G8 as the reference (Nim et al., 2016) showed loss of certain interactions at the level of dimer interface when the serine residue replaces tryptophan at the 1038 position. The authors attributed the resulting increased flexibility as a cause for the change in NBS-TMD crosstalk further leading to reclamation of the transport in the suppressor protein (Banerjee et al., 2018). A more elaborated study was conducted with the L529A mutant and its suppressor L529A-Q1005H, the secondary mutation also happening to be within the signature sequence of the non-catalytic NBS (Banerjee et al., 2020) (Figure 6). Herein, it was observed that while both the mutant and suppressor proteins were ATPase competent, the single Q1005H mutant while reduced in the ATPase activity showed approximately two-fold increased resistance towards majority of the tested substrates when compared to the wild-type protein. The observations made the authors hypothesize a rather direct control of the non-catalytic NBS in substrate-translocation via ATP binding at this site. The authors performed extensive molecular modeling with the help of available asymmetric transporter structures in ATP bound/unbound states as reference. In the ATP-bound structures of MRP1 and CFTR/ABCC7 (Johnson \& Chen, 2018; Z. Zhang et al., 2017, 2018), the authors noted that the glutamine of the Signature sequence interacts with the ribose of the ATP through an H-bond. In contrast, when the position gets occupied by a histidine residue, as the case of 
H1350 in the non-catalytic NBS of CFTR/ABCC7, there is a noticeable displacement of the histidine and neighbors from the ribose by about 1 to $2 \AA$, indicating a rather loose ATP-bound state. Given that the primary defect of substrate binding in case of the L529A variant wasn't restored in the L529A-Q1005H suppressor protein, the authors chose to obtain a mechanistic overview of the possible structural changes that could result in the functional compensation using the ABCG5/G8 structure as a reference. The analysis revealed that Q1005 along with its proximal region indeed contribute to the closing/opening of the non-catalytic NBS, and as a result generates the transmission interface with the coupling and connecting helices, which were identified in the ABCG5/G8 structure (Lee et al., 2016). The loose ATP-bound state, as mentioned earlier in the case of Q1005H substitution, would thus impact the conformational changes at the transmembrane domains leading to transport restoration in the L529A-Q1005H protein (Banerjee et al., 2020).

Mapping all these primary drug-sensitive and secondary rescuing mutants found in the two PDR pumps allows visualization of a structural path from RD2 and HD2 in the $C$-terminal NBD to the $N$-terminal TMD through $\mathrm{CpH} 1$ and $\mathrm{CnH} 1$ (Figure 6). As most of the secondary mutations are localized at the interface of the two NBDs regions forming the non-hydrolytic NBS, and taking into account the drastic change of side chain in each case, it is probable that they alter the affinity of the nucleotide at this site in a way that reduces the lifetime of the nucleotide-bound state for the NBS and/or modify its position with respect to the TMD for restoring the translocation process. The non-catalytic NBS, therefore seems essential to allow or to stabilize a functional organization of the different regions and such role seems to be mediated by the two helicoidal domains, HD1 and HD2 located on both sides of the non-hydrolyzed ATP 
(Figure 6, right lower panel). Whether the same holds true for certain other asymmetric (and symmetrical?) pumps as well, is a question worth asking.

\section{Concluding thoughts and future perspectives}

$\mathrm{ABC}$ transporters with their immense physiological and clinical implications hold the limelight among all the diverse transporter protein superfamilies. The structural diversity in the ABC-superfamily as revealed in the past decade further adds to its importance as models for understanding transport mechanisms in the living system. Besides, the extensive diversity in the substrate repertoire remains a pertinent question for protein biochemists and the transporter research community. As it is true for all other proteins, the mechanistic keys always lie within the transporter structures. Despite the difficulty in unveiling membrane protein structures, the past decade has witnessed an overwhelming number of $\mathrm{ABC}$ transporter structures deposited in the databases, partly due to the significant advancement made on the cryo-EM front. While on the one hand, the increase in structural details has answered many questions related to the transport mechanism of ABC transporters, new questions have also emerged. The structures of ABCG proteins highlighted a novel fold within the ABC exporters and certain important linchpin sites, for instance, the connecting and coupling helices which are essential in the transport mechanism. Since several ABCG exporters function as drug transporters, in-depth details regarding their functioning are need of the hour. In parallel, the insights from the ABCG counterparts in yeast, i.e. the PDR subfamily have aided in understanding the inter- and intradomain crosstalk operative in the ABCG exporters. Furthermore, the asymmetry in NBDs and its functional consequences has also been revealed by the extensive suppressor analysis employed 
with Cdr1p and Pdr5p transporters as highlighted in the chapter. Structures of the toxicity rescuing suppressor proteins should help understanding how the non-hydrolytic NBS modulates the transport of substrates at a molecular level. In addition, future studies may also exploit this combinatorial approach to address further questions about the structure and function of this very important family of ABC exporters and possibly other families as well. The findings would not only advance the overall knowledge of transport mediated by ABC superfamily proteins but also make way for pharmacological interventions.

\section{Acknowledgements}

RP acknowledges funding from the Department of Biotechnology grant no.

[BT/PR14117/BRB/10/1420/2015]. AB acknowledges funding support from the SERB grant no.

SRG/2019/000514. PF acknowledges the Centre National de la Recherche Scientifique (CNRS), Lyon University and the French Research Agency (ANR-CLAMP2- 18-CE11-0002-01) for funding. AM and JP PhDs were funded by ARC1 and EDISS school, respectively.

\section{References}

Alam, A., Kowal, J., Broude, E., Roninson, I., \& Locher, K. P. (2019). Structural insight into substrate and inhibitor discrimination by human P-glycoprotein. Science, 363(6428), 753-756. https://doi.org/10.1126/science.aav7102

Alam, A., Küng, R., Kowal, J., McLeod, R. A., Tremp, N., Broude, E. V., Roninson, I. B., Stahlberg, H., \& Locher, K. P. (2018). Structure of a zosuquidar and UIC2-bound humanmouse chimeric ABCB1. Proceedings of the National Academy of Sciences, 115(9), E1973-E1982. https://doi.org/10.1073/pnas.1717044115 
Aller, S. G., Yu, J., Ward, A., Weng, Y., Chittaboina, S., Zhuo, R., Harrell, P. M., Trinh, Y. T., Zhang, Q., Urbatsch, I. L., \& Chang, G. (2009). Structure of P-glycoprotein reveals a molecular basis for poly-specific drug binding. Science (New York, N.Y.), 323(5922), 1718-1722. https://doi.org/10.1126/science.1168750

Alqawi, O., Bates, S., \& Georges, E. (2004). Arginine482 to threonine mutation in the breast cancer resistance protein ABCG2 inhibits rhodamine 123 transport while increasing binding. The Biochemical Journal, 382(Pt 2), 711-716.

https://doi.org/10.1042/BJ20040355

Ananthaswamy, N., Rutledge, R., Sauna, Z. E., Ambudkar, S. V., Dine, E., Nelson, E., Xia, D., \& Golin, J. (2010). The Signaling Interface of the Yeast Multidrug Transporter Pdr5 Adopts a Cis Conformation, and There Are Functional Overlap and Equivalence of the Deviant and Canonical Q-Loop Residues. Biochemistry, 49(21), 4440-4449. https://doi.org/10.1021/bi100394j

Baghel, P., Rawal, M. K., Khan, M. F., Sen, S., Siddiqui, M. H., Chaptal, V., Falson, P., \& Prasad, R. (2017). Multidrug ABC transporter Cdr1 of Candida albicans harbors specific and overlapping binding sites for human steroid hormones transport. Biochimica et Biophysica Acta (BBA) - Biomembranes, 1859(10), 1778-1789. https://doi.org/10.1016/j.bbamem.2017.05.011

Banerjee, A., Moreno, A., Khan, M. F., Nair, R., Sharma, S., Sen, S., Mondal, A. K., Pata, J., Orelle, C., Falson, P., \& Prasad, R. (2020). Cdr1p highlights the role of the nonhydrolytic ATP-binding site in driving drug translocation in asymmetric ABC pumps. 
Biochimica et Biophysica Acta (BBA) - Biomembranes, 1862(2), 183131. https://doi.org/10.1016/j.bbamem.2019.183131

Banerjee, A., Shah, A. H., Redhu, A. K., Moreno, A., Falson, P., \& Prasad, R. (2018). W1038 near D-loop of NBD2 is a focal point for inter-domain communication in multidrug transporter Cdr1 of Candida albicans. Biochimica et Biophysica Acta (BBA) Biomembranes, 1860(5), 965-972. https://doi.org/10.1016/j.bbamem.2018.01.022

Basso, C., Vergani, P., Nairn, A. C., \& Gadsby, D. C. (2003). Prolonged Nonhydrolytic Interaction of Nucleotide with CFTR's NH 2 -terminal Nucleotide Binding Domain and its Role in Channel Gating. The Journal of General Physiology, 122(3), 333-348. https://doi.org/10.1085/jgp.200308798

Berge, K. E., Tian, H., Graf, G. A., Yu, L., Grishin, N. V., Schultz, J., Kwiterovich, P., Shan, B., Barnes, R., \& Hobbs, H. H. (2000). Accumulation of Dietary Cholesterol in Sitosterolemia Caused by Mutations in Adjacent ABC Transporters. Science, 290(5497), 1771-1775. https://doi.org/10.1126/science.290.5497.1771

Bryan, J., Muñoz, A., Zhang, X., Düfer, M., Drews, G., Krippeit-Drews, P., \& Aguilar-Bryan, L. (2007). ABCC 8 and ABCC9: ABC transporters that regulate K+ channels. Pflügers Archiv - European Journal of Physiology, 453(5), 703-718. https://doi.org/10.1007/s00424-006-0116-z

Chen, Z.-S., Robey, R. W., Belinsky, M. G., Shchaveleva, I., Ren, X.-Q., Sugimoto, Y., Ross, D. D., Bates, S. E., \& Kruh, G. D. (2003). Transport of methotrexate, methotrexate polyglutamates, and 17beta-estradiol 17-(beta-D-glucuronide) by ABCG2: Effects of 
acquired mutations at R482 on methotrexate transport. Cancer Research, 63(14), 40484054.

Dawson, R. J. P., \& Locher, K. P. (2006). Structure of a bacterial multidrug ABC transporter. Nature, 443(7108), 180-185. https://doi.org/10.1038/nature05155

Dean, M., \& Annilo, T. (2005). Evolution of the atp-binding cassette (abc) transporter superfamily in vertebrates. Annual Review of Genomics and Human Genetics, 6(1), 123142. https://doi.org/10.1146/annurev.genom.6.080604.162122

Desuzinges-Mandon, E., Arnaud, O., Martinez, L., Huché, F., Di Pietro, A., \& Falson, P. (2010). ABCG2 transports and transfers heme to albumin through its large extracellular loop. The Journal of Biological Chemistry, 285(43), 33123-33133. https://doi.org/10.1074/jbc.M110.139170

Downes, M. T., Mehla, J., Ananthaswamy, N., Wakschlag, A., Lamonde, M., Dine, E., Ambudkar, S. V., \& Golin, J. (2013). The transmission interface of the saccharomyces cerevisiae multidrug transporter Pdr5: Val-656 located in intracellular loop 2 plays a major role in Drug resistance. Agents, Antimicrobial and Chemotherapy, 57(2), 10251034. https://doi.org/10.1128/AAC.02133-12

Doyle, L. A., \& Ross, D. D. (2003). Multidrug resistance mediated by the breast cancer resistance protein BCRP (ABCG2). Oncogene, 22(47), 7340-7358. https://doi.org/10.1038/sj.onc.1206938

Eggensperger, S., \& Tampé, R. (2015). The transporter associated with antigen processing: A key player in adaptive immunity. Biological Chemistry, 396(9-10), 1059-1072. https://doi.org/10.1515/hsz-2014-0320 
Ejendal, K. F. K., Diop, N. K., Schweiger, L. C., \& Hrycyna, C. A. (2006). The nature of amino acid 482 of human ABCG2 affects substrate transport and ATP hydrolysis but not substrate binding. Protein Science : A Publication of the Protein Society, 15(7), 15971607. https://doi.org/10.1110/ps.051998406

Elkind, N. B., Szentpétery, Z., Apáti, Á., Özvegy-Laczka, C., Várady, G., Ujhelly, O., Szabó, K., Homolya, L., Váradi, A., Buday, L., Kéri, G., Német, K., \& Sarkadi, B. (2005). Multidrug Transporter ABCG2 Prevents Tumor Cell Death Induced by the Epidermal Growth Factor Receptor Inhibitor Iressa (ZD1839, Gefitinib). Cancer Research, 65(5), 1770-1777. https://doi.org/10.1158/0008-5472.CAN-04-3303

Ernst, R., Kueppers, P., Klein, C. M., Schwarzmueller, T., Kuchler, K., \& Schmitt, L. (2008). A mutation of the H-loop selectively affects rhodamine transport by the yeast multidrug ABC transporter Pdr5. Proc Natl Acad Sci U S, A., 105(13), 5069-5074. https://doi.org/10.1073/pnas.0800191105

Ernst, R., Kueppers, P., Stindt, J., Kuchler, K., \& Schmitt, L. (2010). Multidrug efflux pumps: Substrate selection in ATP-binding cassette multidrug efflux pumps-first come, first served? Journal, F. E. B. S., 277(3), 540-549. https://doi.org/10.1111/j.17424658.2009.07485.x

Ford, R. C., \& Beis, K. (2019). Learning the ABCs one at a time: Structure and mechanism of ABC transporters. Transactions, Biochemical Society, 47(1), 23-36. https://doi.org/10.1042/BST20180147

Furman, C., Mehla, J., Ananthaswamy, N., Arya, N., Kulesh, B., Kovach, I., Ambudkar, S. V., \& Golin, J. (2013). The Deviant ATP-binding Site of the Multidrug Efflux Pump Pdr5 Plays 
an Active Role in the Transport Cycle. The Journal of Biological Chemistry, 288(42), 30420-30431. https://doi.org/10.1074/jbc.M113.494682

Furuta, T., Sato, Y., \& Sakurai, M. (2016). Structural Dynamics of the Heterodimeric ABC Transporter TM287/288 Induced by ATP and Substrate Binding. Biochemistry, 55(48), 6730-6738. https://doi.org/10.1021/acs.biochem.6b00947

Gao, M., Cui, H.-R., Loe, D. W., Grant, C. E., Almquist, K. C., Cole, S. P. C., \& Deeley, R. G. (2000). Comparison of the Functional Characteristics of the Nucleotide Binding Domains of Multidrug Resistance Protein 1. Journal of Biological Chemistry, 275(17), 1309813108. https://doi.org/10.1074/jbc.275.17.13098

Golin, J., \& Ambudkar, S. V. V. (2015). The multidrug transporter Pdr5 on the 25Itextsuperscriptth anniversary of its discovery: An important model for the study of asymmetric ABC transporters. Biochem, J., 467(3), 353-363. https://doi.org/10.1042/BJ20150042

Grossmann, N., Vakkasoglu, A. S., Hulpke, S., Abele, R., Gaudet, R., \& Tampé, R. (2014). Mechanistic determinants of the directionality and energetics of active export by a heterodimeric ABC transporter. Nature Communications, 5(1), 1-10. https://doi.org/10.1038/ncomms6419

Gupta, R. P., Kueppers, P., Hanekop, N., \& Schmitt, L. (2014). Generating Symmetry in the Asymmetric ATP-binding Cassette (ABC) Transporter Pdr5 from Saccharomyces cerevisiae. The Journal of Biological Chemistry, 289(22), 15272-15279. https://doi.org/10.1074/jbc.M114.553065 
Gutmann, H., Hruz, P., Zimmermann, C., Beglinger, C., \& Drewe, J. (2005). Distribution of breast cancer resistance protein (BCRP/ABCG2) mRNA expression along the human GI tract. Biochemical Pharmacology, 70(5), 695-699. https://doi.org/10.1016/j.bcp.2005.05.031

Higgins, C. F. (2001). ABC transporters: Physiology, structure and mechanism - an overview. Research in Microbiology, 152(3), 205-210. https://doi.org/10.1016/S09232508(01)01193-7

Hohl, M., Hurlimann, L. M., Bohm, S., Schoppe, J., Grutter, M. G., Bordignon, E., \& Seeger, M. A. (2014). Structural basis for allosteric cross-talk between the asymmetric nucleotide binding sites of a heterodimeric ABC exporter. Of the National Academy of Sciences, Proceedings, 111(30), 11025-11030. https://doi.org/10.1073/pnas.1400485111

Hohl, Michael, Briand, C., Grütter, M. G., \& Seeger, M. A. (2012). Crystal structure of a heterodimeric ABC transporter in its inward-facing conformation. Nature Structural \& Molecular Biology, 19(4), 395-402. https://doi.org/10.1038/nsmb.2267

Holland, I. B. (2011). ABC transporters, mechanisms and biology: An overview. Essays in Biochemistry, 50(1), 1-17. https://doi.org/10.1042/bse0500001

Hutter, C. A. J., Timachi, M. H., Hürlimann, L. M., Zimmermann, I., Egloff, P., Göddeke, H., Kucher, S., Štefanić, S., Karttunen, M., Schäfer, L. V., Bordignon, E., \& Seeger, M. A. (2019). The extracellular gate shapes the energy profile of an ABC exporter. Nature Communications, 10. https://doi.org/10.1038/s41467-019-09892-6 
Hyde, S. C., Emsley, P., Mimmack, M. M., Gileadi, U., Pearcet, S. R., Gallaghert, M. P., Gill, D. R., Hubbard, R. E., \& Higgins, C. F. (1990). Structural model of AlP-binding proteins associated with cystic fibrosis, multidrug resistance and bacterial transport. 346, 4.

Jackson, S. M., Manolaridis, I., Kowal, J., Zechner, M., Taylor, N. M. I., Bause, M., Bauer, S., Bartholomaeus, R., Bernhardt, G., Koenig, B., Buschauer, A., Stahlberg, H., Altmann, K.-H., \& Locher, K. P. (2018). Structural basis of small-molecule inhibition of human multidrug transporter ABCG2. Nature Structural \& Molecular Biology, 25(4), 333-340. https://doi.org/10.1038/s41594-018-0049-1

Jardetzky, O. (1966). Simple Allosteric Model for Membrane Pumps. Nature, 211(5052), 969970. https://doi.org/10.1038/211969a0

Jeong, C.-B., Kim, H.-S., Kang, H.-M., \& Lee, J.-S. (2017). ATP-binding cassette (ABC) proteins in aquatic invertebrates: Evolutionary significance and application in marine ecotoxicology. Aquatic Toxicology, 185, 29-39. https://doi.org/10.1016/j.aquatox.2017.01.013

Jin, M. S., Oldham, M. L., Zhang, Q., \& Chen, J. (2012). Crystal structure of the multidrug transporter P-glycoprotein from Caenorhabditis elegans. Nature, 490(7421), 566-569. https://doi.org/10.1038/nature1 1448

Johnson, Z. L., \& Chen, J. (2017). Structural Basis of Substrate Recognition by the Multidrug Resistance Protein MRP1. Cell, 168(6), 1075-1085.e9. https://doi.org/10.1016/j.cell.2017.01.041

Johnson, Z. L., \& Chen, J. (2018). ATP Binding Enables Substrate Release from Multidrug Resistance Protein 1. Cell, 172(1-2), 81-89. https://doi.org/10.1016/j.cell.2017.12.005 
Jonker, J. W., Buitelaar, M., Wagenaar, E., Van Der Valk, M. A., Scheffer, G. L., Scheper, R. J., Plosch, T., Kuipers, F., Elferink, R. P. J. O., Rosing, H., Beijnen, J. H., \& Schinkel, A. H. (2002). The breast cancer resistance protein protects against a major chlorophyll-derived dietary phototoxin and protoporphyria. Proceedings of the National Academy of Sciences of the United States of America, 99(24), 15649-15654.

https://doi.org/10.1073/pnas.202607599

Khunweeraphong, N., Szöllősi, D., Stockner, T., \& Kuchler, K. (2019). The ABCG2 multidrug transporter is a pump gated by a valve and an extracellular lid. Nature Communications, 10. https://doi.org/10.1038/s41467-019-13302-2

Kim, Y., \& Chen, J. (2018). Molecular structure of human P-glycoprotein in the ATP-bound, outward-facing conformation. Science, 359(6378), 915-919. https://doi.org/10.1126/science.aar7389

Krishnamurthy, P., \& Schuetz, J. D. (2006). Role of ABCG2/BCRP in biology and medicine. Annual Review of Pharmacology and Toxicology, 46, 381-410. https://doi.org/10.1146/annurev.pharmtox.46.120604.141238

Krishnamurthy, Partha, Ross, D. D., Nakanishi, T., Bailey-Dell, K., Zhou, S., Mercer, K. E., Sarkadi, B., Sorrentino, B. P., \& Schuetz, J. D. (2004). The stem cell marker Bcrp/ABCG2 enhances hypoxic cell survival through interactions with heme. The Journal of Biological Chemistry, 279(23), 24218-24225.

https://doi.org/10.1074/jbc.M313599200 
Krishnamurthy, Partha, Xie, T., \& Schuetz, J. D. (2007). The role of transporters in cellular heme and porphyrin homeostasis. Pharmacology \& Therapeutics, 114(3), 345-358. https://doi.org/10.1016/j.pharmthera.2007.02.001

Kumari, S., Kumar, M., Khandelwal, N. K., Kumari, P., Varma, M., Vishwakarma, P., Shahi, G., Sharma, S., Lynn, A. M., Prasad, R., \& Gaur, N. A. (2018). ABC transportome inventory of human pathogenic yeast Candida glabrata: Phylogenetic and expression analysis. PLoS, O. N. E., 13(8), 1-21. https://doi.org/10.1371/journal.pone.0202993

Lamping, E., Baret, P. V., Holmes, A. R., Monk, B. C., Goffeau, A., \& Cannon, R. D. (2010). Fungal PDR transporters: Phylogeny, topology, motifs and function. Genetics, Fungal and Biology, 47(2), 1-36. https://doi.org/10.1016/j.fgb.2009.10.007.Fungal

Lee, J. Y., Yang, J. G., Zhitnitsky, D., Lewinson, O., \& Rees, D. C. (2014). Structural basis for heavy metal detoxification by an Atm1-type ABC exporter. Science (New York, N.Y.), 343(6175), 1133-1136. https://doi.org/10.1126/science.1246489

Lee, J.-Y., Kinch, L. N., Borek, D. M., Wang, J., Wang, J., Urbatsch, I. L., Xie, X.-S., Grishin, N. V., Cohen, J. C., Otwinowski, Z., Hobbs, H. H., \& Rosenbaum, D. M. (2016). Crystal structure of the human sterol transporter ABCG5/ABCG8. Nature, 533(7604), 561-564. https://doi.org/10.1038/nature17666

Liu, F., Zhang, Z., Csanády, L., Gadsby, D. C., \& Chen, J. (2017). Molecular Structure of the Human CFTR Ion Channel. Cell, 169(1), 85-95.e8. https://doi.org/10.1016/j.cell.2017.02.024

Lu, K., Lee, M.-H., Hazard, S., Brooks-Wilson, A., Hidaka, H., Kojima, H., Ose, L., Stalenhoef, A. F. H., Mietinnen, T., Bjorkhem, I., Bruckert, E., Pandya, A., Brewer, Jr., H. B., Salen, 
G., Dean, M., Srivastava, A., \& Patel, S. B. (2001). Two Genes That Map to the STSL Locus Cause Sitosterolemia: Genomic Structure and Spectrum of Mutations Involving Sterolin-1 and Sterolin-2, Encoded by ABCG5 and ABCG8, Respectively. American Journal of Human Genetics, 69(2), 278-290.

Luckenbach, T., Fischer, S., \& Sturm, A. (2014). Current advances on ABC drug transporters in fish. Comparative Biochemistry and Physiology Part C: Toxicology \& Pharmacology, 165, 28-52. https://doi.org/10.1016/j.cbpc.2014.05.002

Manolaridis, I., Jackson, S. M., Taylor, N. M. I., Kowal, J., Stahlberg, H., \& Locher, K. P. (2018). Cryo-EM structures of a human ABCG2 mutant trapped in ATP-bound and substrate-bound states. Nature, 563(7731), 426-430. https://doi.org/10.1038/s41586-0180680-3

Mao, Q. (2008). BCRP/ABCG2 in the Placenta: Expression, Function and Regulation. Pharmaceutical Research, 25(6), 1244-1255. https://doi.org/10.1007/s11095-008-9537-z Martinez, L., Arnaud, O., Henin, E., Tao, H., Chaptal, V., Doshi, R., Andrieu, T., Dussurgey, S., Tod, M., Di Pietro, A., Zhang, Q., Chang, G., \& Falson, P. (2014). Understanding polyspecificity within the substrate-binding cavity of the human multidrug resistance Pglycoprotein. The FEBS Journal, 281(3), 673-682. https://doi.org/10.1111/febs.12613

Moncalian, G., Lengsfeld, B., Bhaskara, V., Hopfner, K.-P., Karcher, A., Alden, E., Tainer, J. A., \& Paull, T. T. (2004). The rad50 signature motif: Essential to ATP binding and biological function. Journal of Molecular Biology, 335(4), 937-951. https://doi.org/10.1016/j.jmb.2003.11.026 
Moreno, A., Banerjee, A., Prasad, R., \& Falson, P. (2019). PDR-like ABC systems in pathogenic fungi. Research in Microbiology, 170(8), 417-425.

https://doi.org/10.1016/j.resmic.2019.09.002

Navarro-Quiles, C., Mateo-Bonmatí, E., \& Micol, J. L. (2018). ABCE Proteins: From Molecules to Development. Frontiers in Plant Science, 9. https://doi.org/10.3389/fpls.2018.01125

Nim, S., Lobato, L. G., Moreno, A., Chaptal, V., Rawal, M. K., Falson, P., \& Prasad, R. (2016). Atomic modelling and systematic mutagenesis identify residues in multiple drug binding sites that are essential for drug resistance in the major Candida transporter Cdr1. Et Biophysica Acta Biomembranes, Biochimica, 1858(11), 2858-2870. https://doi.org/10.1016/j.bbamem.2016.08.011

Oldham, M. L., \& Chen, J. (2011). Snapshots of the maltose transporter during ATP hydrolysis. Proceedings of the National Academy of Sciences of the United States of America, 108(37), 15152-15156. https://doi.org/10.1073/pnas.1108858108

Orelle, Cedric, Alvarez, F. J. D., Oldham, M. L., Orelle, A., Wiley, T. E., Chen, J., \& Davidson, A. L. (2010). Dynamics of alpha-helical subdomain rotation in the intact maltose ATPbinding cassette transporter. Of the National Academy of Sciences of the United States of America, Proceedings, 107(47), 20293-20298. https://doi.org/10.1073/pnas.1006544107

Orelle, Cédric, Mathieu, K., \& Jault, J.-M. (2019). Multidrug ABC transporters in bacteria. Research in Microbiology, 170(8), 381-391. https://doi.org/10.1016/j.resmic.2019.06.001

Orlando, B. J., \& Liao, M. (2020). ABCG2 transports anticancer drugs via a closed-to-open switch. Nature Communications, 11(1), 2264. https://doi.org/10.1038/s41467-020-161552 
Özvegy, C., Váradi, A., \& Sarkadi, B. (2002). Characterization of Drug Transport, ATP Hydrolysis, and Nucleotide Trapping by the Human ABCG2 Multidrug Transporter modulation of substrate specificity by a point mutation. Journal of Biological Chemistry, 277(50), 47980-47990. https://doi.org/10.1074/jbc.M207857200

Popovic, M., Zaja, R., Loncar, J., \& Smital, T. (2010). A novel ABC transporter: The first insight into zebrafish (Danio rerio) ABCH1. Marine Environmental Research, 69, S11-S13. https://doi.org/10.1016/j.marenvres.2009.10.016

Prasad, R., Balzi, E., Banerjee, A., \& Khandelwal, N. K. (2019). All about CDR transporters: Past, present, and future. Yeast, 36(4), 223-233. https://doi.org/10.1002/yea.3356

Prasad, R., Banerjee, A., Khandelwa, N. K., Dhamgaye, S., Khandelwal, N. K., \& Dhamgaye, S. (2015). The ABCs of Candida albicans multidrug transporter Cdr1. Cell, Eukaryotic, 14(12), 1154-1164. https://doi.org/10.1128/EC.00137-15

Prasad, R., Khandelwal, N. K., \& Banerjee, A. (2016). Yeast ABC transporters in lipid trafficking. Genetics, Fungal and Biology, 93, 25-34. https://doi.org/10.1016/j.fgb.2016.05.008

Procko, E., Ferrin-O’Connell, I., Ng, S.-L., \& Gaudet, R. (2006). Distinct Structural and Functional Properties of the ATPase Sites in an Asymmetric ABC Transporter. Molecular Cell, 24(1), 51-62. https://doi.org/10.1016/j.molcel.2006.07.034

Qiu, Y., Liu, H., Qing, Y., Yang, M., Tan, X., Zhao, M., Lin, M., \& Zhou, J. (2014). The ABCG2 gene Q141K polymorphism contributes to an increased risk of gout: A metaanalysis of 2185 cases. Modern Rheumatology, 24(5), 829-834. https://doi.org/10.3109/14397595.2013.875639 
Rawal, M. K., Khan, M. F., Kapoor, K., Goyal, N., Sen, S., Saxena, A. K., Lynn, A. M., Tyndall, J. D. A., Monk, B. C., Cannon, R. D., Komath, S. S., \& Prasad, R. (2013). Insight into pleiotropic drug resistance ATP-binding cassette pump drug transport through mutagenesis of Cdr1p transmembrane domains. The Journal of Biological Chemistry, 288(34), 24480-24493. https://doi.org/10.1074/jbc.M113.488353

Redhu, A. K., Banerjee, A., Shah, A. H., Moreno, A., Rawal, M. K., Nair, R., Falson, P., \& Prasad, R. (2018). Molecular Basis of Substrate Polyspecificity of the Candida albicans Mdr1p Multidrug/H+ Antiporter. Journal of Molecular Biology, 430(5), 682-694. https://doi.org/10.1016/j.jmb.2018.01.005

Rees, D. C., Johnson, E., \& Lewinson, O. (2009). ABC transporters: The power to change. Nature Reviews. Molecular Cell Biology, 10(3), 218-227. https://doi.org/10.1038/nrm2646

Rich, D. P., Anderson, M. P., Gregory, R. J., Cheng, S. H., Paul, S., Jefferson, D. M., McCann, J. D., Klinger, K. W., Smith, A. E., \& Welsh, M. J. (1990). Expression of cystic fibrosis transmembrane conductance regulator corrects defective chloride channel regulation in cystic fibrosis airway epithelial cells. Nature, 347(6291), 358-363. https://doi.org/10.1038/347358a0

Robey, R. W., Pluchino, K. M., Hall, M. D., Fojo, A. T., Bates, S. E., \& Gottesman, M. M. (2018). Revisiting the role of ABC transporters in multidrug-resistant cancer. Nature Reviews. Cancer, 18(7), 452-464. https://doi.org/10.1038/s41568-018-0005-8 
Robey, R. W., Steadman, K., Polgar, O., Morisaki, K., Blayney, M., Mistry, P., \& Bates, S. E. (2004). Pheophorbide a is a specific probe for ABCG2 function and inhibition. Cancer Research, 64(4), 1242-1246. https://doi.org/10.1158/0008-5472.can-03-3298

Roe, M., Folkes, A., Ashworth, P., Brumwell, J., Chima, L., Hunjan, S., Pretswell, I., Dangerfield, W., Ryder, H., \& Charlton, P. (1999). Reversal of P-glycoprotein mediated multidrug resistance by novel anthranilamide derivatives. Bioorganic \& Medicinal Chemistry Letters, 9(4), 595-600. https://doi.org/10.1016/s0960-894x(99)00030-x

Saini, P., Gaur, N. A., \& Prasad, R. (2006). Chimeras of the ABC drug transporter Cdr1p reveal functional indispensability of transmembrane domains and nucleotide-binding domains, but transmembrane segment 12 is replaceable with the corresponding homologous region of the non-drug transporter Cdr3p. Microbiology, 152(5), 1559-1573. https://doi.org/10.1099/mic.0.28471-0

Saraste, M., Sibbald, P. R., \& Wittinghofer, A. (1990). The P-loop-A common motif in ATPand GTP-binding proteins. Trends in Biochemical Sciences, 15(11), 430-434. https://doi.org/10.1016/0968-0004(90)90281-F

Sarkadi, B., Ozvegy-Laczka, C., Német, K., \& Váradi, A. (2004). ABCG2-A transporter for all seasons. FEBS Letters, 567(1), 116-120. https://doi.org/10.1016/j.febslet.2004.03.123

Sauna, Z. E., Bohn, S. S., Rutledge, R., Dougherty, M. P., Cronin, S., May, L., Xia, D., Ambudkar, S. V., \& Golin, J. (2008). Mutations Define Cross-talk between the Nterminal Nucleotide-binding Domain and Transmembrane Helix-2 of the Yeast Multidrug Transporter Pdr5 possible conservation of a signaling interface for coupling atp 
hydrolysis to drug transport. Journal of Biological Chemistry, 283(50), 35010-35022. https://doi.org/10.1074/jbc.M806446200

Shah, A. H., Banerjee, A., Rawal, M. K., Saxena, A. K., Mondal, A. K., \& Prasad, R. (2015). $\mathrm{ABC}$ transporter cdr1p harbors charged residues in the intracellular loop and nucleotidebinding domain critical for protein trafficking and drug resistance. Research, F. E. M. S. Yeast, 15(5), 1-10. https://doi.org/10.1093/femsyr/fov036

Shah, A. H., Rawal, M. K., Dhamgaye, S., Komath, S. S., Saxena, A. K., \& Prasad, R. (2015). Mutational Analysis of Intracellular Loops Identify Cross Talk with Nucleotide Binding Domains of Yeast ABC Transporter Cdr1p. Group, Nature Publishing, 5(May), 1-17. https://doi.org/10.1038/srep11211

Smith, P. C., Karpowich, N., Millen, L., Moody, J. E., Rosen, J., Thomas, P. J., \& Hunt, J. F. (2002). ATP Binding to the Motor Domain from an ABC Transporter Drives Formation of a Nucleotide Sandwich Dimer. Molecular Cell, 10(1), 139-149.

Sorum, B., Töröcsik, B., \& Csanády, L. (2017). Asymmetry of movements in CFTR's two ATP sites during pore opening serves their distinct functions. ELife, 6 . https://doi.org/10.7554/eLife.29013

Srinivasan, V., Pierik, A. J., \& Lill, R. (2014). Crystal structures of nucleotide-free and glutathione-bound mitochondrial ABC transporter Atm1. Science (New York, N.Y.), 343(6175), 1137-1140. https://doi.org/10.1126/science.1246729

Szöllősi, D., Rose-Sperling, D., Hellmich, U. A., \& Stockner, T. (2018). Comparison of mechanistic transport cycle models of ABC exporters. Et Biophysica Acta 
Biomembranes, Biochimica, 1860(4), 818-832.

https://doi.org/10.1016/j.bbamem.2017.10.028

Tamaki, A., Ierano, C., Szakacs, G., Robey, R. W., \& Bates, S. E. (2011). The controversial role of ABC transporters in clinical oncology. Essays in Biochemistry, 50(1), 209-232. https://doi.org/10.1042/bse0500209

Taylor, N. M. I., Manolaridis, I., Jackson, S. M., Kowal, J., Stahlberg, H., \& Locher, K. P. (2017). Structure of the human multidrug transporter ABCG2. Nature, 546(7659), 504509. https://doi.org/10.1038/nature22345

Thomas, C., \& Tampé, R. (2020). Structural and Mechanistic Principles of ABC Transporters. Annual Review of Biochemistry, 89(1), 605-636. https://doi.org/10.1146/annurevbiochem-011520-105201

Tsai, M.-F., Jih, K.-Y., Shimizu, H., Li, M., \& Hwang, T.-C. (2010). Optimization of the Degenerated Interfacial ATP Binding Site Improves the Function of Disease-related Mutant Cystic Fibrosis Transmembrane Conductance Regulator (CFTR) Channels. Journal of Biological Chemistry, 285(48), 37663-37671. https://doi.org/10.1074/jbc.M110.172817

Urbatsch, I. L., \& Senior, A. E. (1995). Effects of lipids on ATPase activity of purified Chinese hamster P-glycoprotein. Archives of Biochemistry and Biophysics, 316(1), 135-140. https://doi.org/10.1006/abbi.1995.1020

van Loevezijn, A., Allen, J. D., Schinkel, A. H., \& Koomen, G. J. (2001). Inhibition of BCRPmediated drug efflux by fumitremorgin-type indolyl diketopiperazines. Bioorganic \& 
Medicinal Chemistry Letters, 11(1), 29-32. https://doi.org/10.1016/s0960-

$894 x(00) 00588-6$

Vergani, P., Lockless, S. W., Nairn, A. C., \& Gadsby, D. C. (2005). CFTR channel opening by ATP-driven tight dimerization of its nucleotide-binding domains. Nature, 433(7028), 876-880. https://doi.org/10.1038/nature03313

Vergani, P., Nairn, A. C., \& Gadsby, D. C. (2003). On the Mechanism of MgATP-dependent Gating of CFTR Cl- Channels. The Journal of General Physiology, 121(1), 17-36. https://doi.org/10.1085/jgp.20028673

Verrier, P. J., Bird, D., Burla, B., Dassa, E., Forestier, C., Geisler, M., Klein, M., Kolukisaoglu, Ü., Lee, Y., Martinoia, E., Murphy, A., Rea, P. A., Samuels, L., Schulz, B., Spalding, E. P., Yazaki, K., \& Theodoulou, F. L. (2008). Plant ABC proteins - a unified nomenclature and updated inventory. Trends in Plant Science, 13(4), 151-159. https://doi.org/10.1016/j.tplants.2008.02.001

Walker, J. E., Saraste, M., Runswick, M. J., \& Gay, N. J. (1982). Distantly related sequences in the alpha- and beta-subunits of ATP synthase, myosin, kinases and other ATP-requiring enzymes and a common nucleotide binding fold. The EMBO Journal, 1(8), 945-951.

Wang, L., Johnson, Z. L., Wasserman, M. R., Levring, J., Chen, J., \& Liu, S. (2020).

Characterization of the kinetic cycle of an $\mathrm{ABC}$ transporter by single-molecule and cryoEM analyses. ELife, 9, e56451. https://doi.org/10.7554/eLife.56451

Ward, A. B., Szewczyk, P., Grimard, V., Lee, C.-W., Martinez, L., Doshi, R., Caya, A., Villaluz, M., Pardon, E., Cregger, C., Swartz, D. J., Falson, P. G., Urbatsch, I. L., Govaerts, C., Steyaert, J., \& Chang, G. (2013). Structures of P-glycoprotein reveal its conformational 
flexibility and an epitope on the nucleotide-binding domain. Proceedings of the National Academy of Sciences of the United States of America, 110(33), 13386-13391. https://doi.org/10.1073/pnas.1309275110

Ward, A., Reyes, C. L., Yu, J., Roth, C. B., \& Chang, G. (2007). Flexibility in the ABC transporter MsbA: Alternating access with a twist. Proceedings of the National Academy of Sciences of the United States of America, 104(48), 19005-19010. https://doi.org/10.1073/pnas.0709388104

Woodward, O. M., Köttgen, A., Coresh, J., Boerwinkle, E., Guggino, W. B., \& Köttgen, M. (2009). Identification of a urate transporter, ABCG2, with a common functional polymorphism causing gout. Proceedings of the National Academy of Sciences of the United States of America, 106(25), 10338-10342. https://doi.org/10.1073/pnas.0901249106

Yang, R., Hou, Y., Campbell, C. A., Palaniyandi, K., Zhao, Q., Bordner, A. J., \& Chang, X. (2011). Glutamine residues in Q-loops of multidrug resistance protein MRP1 contribute to ATP binding via interaction with metal cofactor. Biochimica et Biophysica Acta (BBA) - Biomembranes, 1808(7), 1790-1796. https://doi.org/10.1016/j.bbamem.2011.02.004

Ye, J., Osborne, A. R., Groll, M., \& Rapoport, T. A. (2004). RecA-like motor ATPasesLessons from structures. Et Biophysica Acta Bioenergetics, Biochimica, 1659(1), 1-18. https://doi.org/10.1016/j.bbabio.2004.06.003

Zaitseva, J., Jenewein, S., Jumpertz, T., Holland, I. B., \& Schmitt, L. (2005). H662 is the linchpin of ATP hydrolysis in the nucleotide-binding domain of the ABC transporter HlyB. The EMBO Journal, 24(11), 1901-1910. https://doi.org/10.1038/sj.emboj.7600657 
Zhang, J., Yu, Y.-C., Yeh, J.-T., \& Hwang, T.-C. (2018). Functional characterization reveals that zebrafish CFTR prefers to occupy closed channel conformations. PLoS ONE, 13(12). https://doi.org/10.1371/journal.pone.0209862

Zhang, Z., Liu, F., \& Chen, J. (2017). Conformational Changes of CFTR upon Phosphorylation and ATP Binding. Cell, 170(3), 483-491.e8. https://doi.org/10.1016/j.cell.2017.06.041 Zhang, Z., Liu, F., \& Chen, J. (2018). Molecular structure of the ATP-bound, phosphorylated human CFTR. Proceedings of the National Academy of Sciences of the United States of America, 115(50), 12757-12762. https://doi.org/10.1073/pnas.1815287115

\section{Table and Figures legends}

\section{Table 1. Conserved sequence motifs of the nucleotide binding domains of ABC}

proteins. Residues are identified by their 1-letter code, $\mathrm{h}=$ hydrophobic residue, $\mathrm{x}=$ any amino acid. Based on Eggensperger and Tampé, 2015.

Figure 1. Cartoon representations of type I and type II ABC exporters structures, in inward- and outward-facing conformations (IFC, OFC). Human $\mathrm{ABCB} 1, \mathrm{ABCC} 7$ and ABCCC 1 on the top belong to the type I fold. They are made of a single polypeptide organized in a pseudo-dimer of two haves (red and blue) forming the different regions, nucleotide-binding domains (NBDs), intracellular domain (ICD) with intracellular loops (ICLs), transmembrane domain (TMD) and extracellular domain (ECD). ABCC7 and $\mathrm{ABCC} 1$ display an additional regulatory domain and a transmembrane domain, respectively. Human ABCG5/ABCG8 and 
ABCG2 belong to the type II fold. They are made of two polypeptides making each half of the hetero- or homo- dimer. PDB codes are indicated.

Figure 2. Nucleotide binding and hydrolysis motifs found in ABC transporters. Cartoon representation of the ATP-bound human P-gp E1201Q mutant (PDB ID: 6C0V) (Kim \& Chen, 2018) illustrating the different consensus peptides involved in binding and hydrolysis of the nucleotide. A glutamine residue (red star) in the Walker B motif replaces the glutamate 1201 to prevent ATP hydrolysis and maintain the protein in a pre-hydrolytic state. ATP is shown as sticks and magnesium as a sphere. HD1/HD2: helical domain 1/2 (ABC $\alpha$ subdomain), RD1/RD2: RecA-like domain 1/2 (including ABC $\beta$ subdomain).

Figure 3. Domain organization of type I and type II ABC exporters. Left panels: IFC and $\mathrm{OFC}$ of ABCB1 (top, PDB ID: 6QEX and 6C0V, respectively) (Alam et al., 2019; Kim \& Chen, 2018) and of ABCG2 (bottom, PDB ID: 6VXF and 6HBU, respectively) (Manolaridis et al., 2018; Orlando \& Liao, 2020) illustrate the differences in interdomains connections between the two types of exporters and the major conformational switch involved in substrate transport. Proteins are represented as cartoon with their corresponding surface outlined and colored by domains and structural features. $\mathrm{ATP}-\mathrm{Mg}^{2+}$ are shown as spheres. Right panels: Close view of the ATP-bound dimerized NBDs, as seen from the membrane, with surrounding semi-transparent surface. The coupling helices of both types of exporters make contacts with both the RecA-like and helical subdomains. In type I exporters (top), the connecting helices interact with the RecAlike domain of its opposite NBD. In contrast, the connecting helices of type II exporters (bottom) interact with the helical domain of its corresponding NBD. CnH1/2: connecting helix 1/2, $\mathrm{CpH} 1 / 2$ : coupling helix 1/2, HD1/HD2: helical domain 1/2 (ABC $\alpha$ subdomain), NBD1/2: 
nucleotide binding domain 1/2, RD1/RD2: RecA-like domain 1/2 (including $A B C \beta$ subdomain), TMD1/2: transmembrane domain 1/2.

Figure 4. Details of the substrate-binding pocket of ABCG2. Left panel: mesh representation of ABCG2 (5NJ3) (Taylor et al., 2017) highlighting cavities 1 and 2. So far, no substrate has been found binding to the upper one. Right panels: zoomed cartoon representation of ABCG2 structures in complex either with the inhibitor MZ29 (blue) (6FFC) (Jackson et al., 2018), or the substrate mitoxantrone (red) (6XVI) or imatinib (yellow) (6XVH) (Orlando \& Liao, 2020), seen in the plan of the membrane (top) or seen from the NBDs (bottom).

Figure 5. Shapes of type I and type II substrate-binding pockets. Left: ABCB1 in complex either with taxol (red) (6QEX) (Alam et al., 2019) seen in the plane of membrane (top) or seen from NBDs (bottom), with the interacting residues represented as a mesh (blue), putting in evidence the globular shape of the type I substrate-binding pocket. Right: ABCG2 in complex with its inhibitor MZ29 (red) (6FFC) (Jackson et al., 2018) seen in the plane of membrane (top) or seen from NBDs (bottom), with the interacting residues represented as a mesh (blue), putting in evidence the slit-like shape of the type II substrate-binding pocket, accommodating flat hydrophobic compounds.

Figure 6. Mapping of primary drug-sensitive and secondary rescuing mutants in yeast type II exporters Cdr1p and Pdr5p. Upper panel: 3D IFC models of Cdr1p and Pdr5p (Banerjee et al., 2020) with functional regions colored as described in Figure 3. Primary drugsensitizing mutants are S558Y (Sauna et al., 2008), N242K and E244G (Downes et al., 2013) in Pdr5p, and E597A (Shah et al., 2015; Shah et al., 2015), V532D (Banerjee et al., 2018) and 
L529A (Rawal et al., 2013) in Cdr1p. S558Y in Pdr5p is rescued by the secondary mutations N242K, E244G, D2464, S597I/T, M679L, P596L or G1233D; N242K is rescued by K1016I, V656L, P596L, L1367F, A670S, or I1063M; E244G is rescued by V656L (Sauna et al., 2008; Ananthaswamy et al., 2010; Downes et al., 2013). E597A, V532D and L529A in Cdr1p are rescued by C1041W, R1008I and L1032F for the first one and W1038S and Q1005H, respectively, for the last two (Banerjee et al., 2018; Banerjee et al., 2020). Lower panel, left: OFC model of ATP-Mg bound Cdr1p (Banerjee et al., 2020) colored as above with primary drug-sensitizing and suppressor mutants of Cdr1. Residues corresponding to those of Pdr5p are also displayed with the same color code. Right: zoom to the non-hydrolytic NBS. 